\title{
Geologia e gravimetria de rochas metaultramáficas e metacarbonatitos ediacaranos associados no Complexo Senador Elói de Souza, Província Borborema, NE do Brasil
}

\author{
Geology and gravimetry of Ediacaran metaultramafic rocks and associated \\ metacarbonatites of the Senador Eloi de Souza Complex, Borborema Province, NE Brazil
}

\author{
Marcella Samyla de Miranda Silva' (1), Zorano Sérgio de Souza' ${ }^{1}$ (1), \\ Flávio Lemos de Santana² (D), José Alexandre Paixão da Cunha1 (D) \\ ${ }^{1}$ Universidade Federal do Rio Grande do Norte - UFRN, Departamento de Geologia, Pós-Graduação em Geodinâmica e \\ Geofísica, Rua das Engenharias, s/n, CEP 59078-970, Campus Universitário Lagoa Nova, Natal, RN, BR (marcellasamyla@ \\ gmail.com; zorano@geologia.ufrn.br; alexandrepaixaodacunha@yahoo.com.br) \\ 2UFRN, Departamento de Geofísica, PRH-229, Natal, RN, BR (flavio.geofisica@yahoo.com.br)
}

Recebido em 23 de novembro de 2020; aceito em 10 de setembro de 2021.

\begin{abstract}
Resumo
O Maciço São José do Campestre, com cerca de $6.000 \mathrm{~km}^{2}$, corresponde a um dos fragmentos de crosta continental mais antigos da América do Sul, sendo constituído de ortognaisses, complexos máfico-ultramáficos e metassupracrustais com idades entre 3,41 e 2,70 Ga. O Complexo Senador Elói de Souza corresponde a uma dessas unidades, sendo composto de clinopiroxênio gnaisses, granada paragnaisses, com corpos ultramáficos e carbonatitos associados. Dados geocronológicos U-Pb em zircão sugerem uma idade de cristalização de 600 Ma para esses carbonatitos e piroxenitos. Feições de contato mostram brechas magmáticas, em que fragmentos decimétricos de piroxenito estão imersos em carbonatito de textura holocristalina. As ultramáficas apresentam textura ígnea bem preservada, predomínio de piroxênio cálcico, padrão pouco fracionado de elementos terras raras, com razões $\mathrm{La}_{\mathrm{N}} / \mathrm{Yb}_{\mathrm{N}}$ de $1,5-8,6$ e anomalia negativa de $\mathrm{Eu}(\mathrm{Eu} / \mathrm{Eu} *=0,39-0,88)$. Os carbonatitos são ricos em calcita, tendo flogopita, olivina e diopsídio como fases máficas dominantes, baixas concentrações de elementos terras raras e razões $\mathrm{La}_{\mathrm{N}} / \mathrm{Yb}_{\mathrm{N}}$ de 8,9-49,8. Modelagem gravimétrica $2 \mathrm{D}$ e controle de campo permitem interpretar corpos piroxeníticos elipsoidais de baixa profundidade e carbonatitos de menor expressividade no centro e bordas dos corpos ultramáficos. A integração de novos dados geológicos, geoquímicos e gravimétricos aportados nesta pesquisa mostra-se relevante para a compreensão de eventos ediacaranos no domínio arqueano do Maciço São José do Campestre.
\end{abstract}

Palavras-chave: Piroxenito; Carbonatito; Geoquímica; Gravimetria; Maciço São José do Campestre.

\begin{abstract}
With about 6,000 $\mathrm{km}^{2}$, the São José do Campestre Massif corresponds to one of the oldest remains of continental crust in South America, consisting of clinopyroxene gneisses, mafic-ultramafic complexes, and metasupracrustals with ages between 3.41 and $2.70 \mathrm{Ga}$. The Senador Eloi de Souza Complex corresponds to one of these units, being composed of clinopyroxene gneisses, garnet paragnaisses, and ultramafic bodies and associated carbonatites. U-Pb geochronological data in zircon suggest a crystallization age of $600 \mathrm{Ma}$ for these carbonatites and pyroxenites. Contact features show magmatic breccias, where decimeter-sized fragments of pyroxenite are immersed in carbonatite with holocrystalline texture. The ultramafic rocks have a well-preserved igneous texture, a predominance of calcium pyroxene, a little fractionated pattern of rare earth elements, with $\mathrm{La}_{\mathrm{N}} / \mathrm{Yb}_{\mathrm{N}}$ ratios of $1.5-8.6$ and negative Eu anomaly $\left(\mathrm{Eu} / \mathrm{Eu}^{*}=0.39-0.88\right)$. Carbonatites are rich in calcite, with phlogopite, olivine, and diopside as dominant mafic phases, low concentrations of rare earth elements, with low concentrations of rare earth elements, and $\mathrm{La}_{\mathrm{N}} / \mathrm{Yb}_{\mathrm{N}}$ ratios of 8.9-49.0. 2D gravimetric modeling and field control allow to interpret ellipsoidal pyroxenitic bodies of shallow depth and carbonatites of less expressiveness in the center and edges of these ultramafic bodies. The integration of new geological, geochemical, and gravimetric data from this research is relevant to a better understanding of Ediacaran events in the Archean domain of the São José do Campestre Massif.
\end{abstract}

Keywords: Pyroxenites; Carbonatites; Geochemistry; Gravimetry; São José do Campestre Massif. 


\section{INTRODUÇÃO}

Com cerca de 600 ocorrências mundiais (Woolley e Kjarsgaard, 2009), os carbonatitos são rochas raras que foram definidas por Le Maitre (2002) como de origem ígnea, intrusivas ou extrusivas, compostas de mais de $50 \%$ de minerais carbonáticos e que apresentam menos de $20 \%$ de $\mathrm{SiO}_{2}$ em sua composição química. Segundo Le Bas (1981), a ocorrência de rochas carbonatíticas está intimamente ligada a diatremas vulcânicos e subvulcânicos, e ambientes intraplaca continentais ou oceânicos associados a complexos anelares. É comum a presença de álcali-piroxenitos, ijolitos, nefelinitos, sienitos e fenitos, nos quais os carbonatitos se apresentam na forma de derrames, diques, plugs, cone sheets ou soleiras (Barker, 1989).

O interesse crescente pelo estudo de carbonatitos está diretamente ligado ao seu alto potencial para mineralizações, podendo representar importantes depósitos de fosfato, nióbio, barita, anatásio, magnetita, vermiculita, cobre, urânio, bauxita, fluorita e elementos terras raras (ETR) (Grasso, 2010). Nesse contexto, há um consenso na literatura que carbonatitos possuem altos teores de $\mathrm{Sr}, \mathrm{Ba}, \mathrm{Zr}, \mathrm{Nb}, \mathrm{U}, \mathrm{Th}$ e ETR. Porém, estudos desenvolvidos por Azer et al. (2010) descrevem carbonatitos em Wadi Tarr, no Egito, distintos quimicamente de carbonatitos clássicos, uma vez que não possuem altos teores de $\mathrm{Ba}$, Sr e ETR.

No Brasil, a maior parte dos carbonatitos encontra-se na borda da Bacia do Paraná (Grasso, 2010). Entretanto, ocorrem também em Angicos do Dias (Bahia), Maicuru (Pará), Mutum e Morro de Seis Lagos (Amazonas), com diferentes composições mineralógicas e idades variando do Paleoproterozoico ao Cretáceo Superior. No Maciço São José do Campestre (MSJC), as primeiras referências a rochas carbonatíticas associadas com ultramáficas foram reportadas pelo Serviço Geológico Brasileiro (CPRM) a partir do projeto Fosfato Brasil 2011 (Abram et al., 2011), em pesquisa motivada pela ocorrência de anomalias magnéticas compatíveis com assinaturas de corpos cilíndricos verticais no núcleo arqueano. Posteriormente, Teixeira (2012) e Cunha (2015) descreveram corpos circulares e semicirculares que afloram como blocos de piroxenito e carbonatito com diâmetro entre 300 e 500 m. Datações U-Pb em zircão realizadas por Souza et al. (2018) identificaram zircões herdados em 2,0, 2,7 e 3,3 Ga em amostras de carbonatitos do MSJC descritas por Teixeira (2012) e Cunha (2015), com ocorrência de zircões ediacaranos concordantes de $600 \pm$ $3 \mathrm{Ma}$, interpretada como a idade de cristalização.

A ausência de estudos geoquímicos e geofísicos de piroxenitos e carbonatitos do MSJC motivou a realização do presente trabalho. Assim, são integrados neste estudo informações de campo, caracterização petrográfica, química mineral e de rocha total de carbonatitos e piroxenitos do Complexo Senador Elói de Souza (CSES), bem como um perfil gravimétrico a partir do qual foi realizada uma modelagem 2D, que possibilitou interpretar uma geometria para o corpo ultramáfico e a distribuição dos demais corpos carbonatíticos e piroxeníticos em subsuperfície.

\section{CONTEXTO GEOLÓGICO}

A Província Borborema, Paraíba, localizada no Nordeste brasileiro, é uma unidade geotectônica formada durante a colisão entre os crátons do Oeste da África/São Luiz e São Francisco/Congo-Kasai (Caby, 1989; Caby et al., 1991), e que foi descrita por Almeida et al. (1981) como um embasamento gnáissico-migmatítico de idade arqueana a paleoproterozoica, metassupracrustais e plutônicas neoproterozoicas, com metamorfismo nas fácies xisto verde a anfibolito (localmente granulito) e zonas de cisalhamento de extensão continental delimitando blocos tectônicos. O Domínio Rio Grande do Norte (DRGN) é composto dos domínios São José do Campestre e Rio Piranhas-Seridó, separados pela Zona de Cisalhamento Picuí - João Câmara, limitado a sul pelo Lineamento Patos e a norte pela Bacia Potiguar (Brito Neves et al., 2000). Nele, o MSJC engloba uma área de cerca de $6.000 \mathrm{~km}^{2}$, sendo marcado por diferentes eventos magmáticos descritos por Dantas et al. $(2004,2013)$ e Souza et al. (2016). Datações U-Pb, dados isotópicos e químicos sugerem a contribuição da crosta continental e do manto superior, com ortognaisses arqueanos $(3,4-2,7 \mathrm{Ga}) \mathrm{e}$ paleoproterozoicos $(2,25-2,11 \mathrm{Ga})$ do tipo TTG (Tonalito Trondhjemito - Granodiorito), mas também calcioalcalinos potássicos, além de reciclagem extensiva no Ediacarano (Souza et al., 2016).

O CSES é uma unidade geológica pertencente ao MSJC (Figura 1) composta de rochas máficas e ultramáficas que incluem metagabros, metaclinopiroxenitos e anortositos ricos em granada e oligoclásio e que estão encaixados em gnaisses de composição granítica a tonalítica e tipos máficos representados por hedenbergita e granada com idade de cristalização determinada pelo método U-Pb em zircão de 3,03 Ga, seguido por metamorfismo em 0,6 Ga (Dantas et al., 2004). Tectonicamente, Araújo et al. (2014) descrevem a região como pertencente a um sistema de cisalhamento de domínio estrutural homogêneo, onde as rochas estão dispostas preferencialmente na direção NW-SE. Para esses autores, a associação de hedenbergita ortognaisses e rochas máficas e ultramáficas com o sistema de cisalhamento atuante sugere reativação e retrabalhamento ocorridos durante a Orogênese Brasiliana/Panafricana.

Diante da ocorrência de anomalias magnéticas próximas ao município de Senador Elói de Souza (Rio Grande do Norte), a CPRM, por meio do Projeto Fosfato Brasil (Abram et al., 2011), selecionou dois alvos geológicos para estudo, que foram caracterizados por corpos alinhados na 


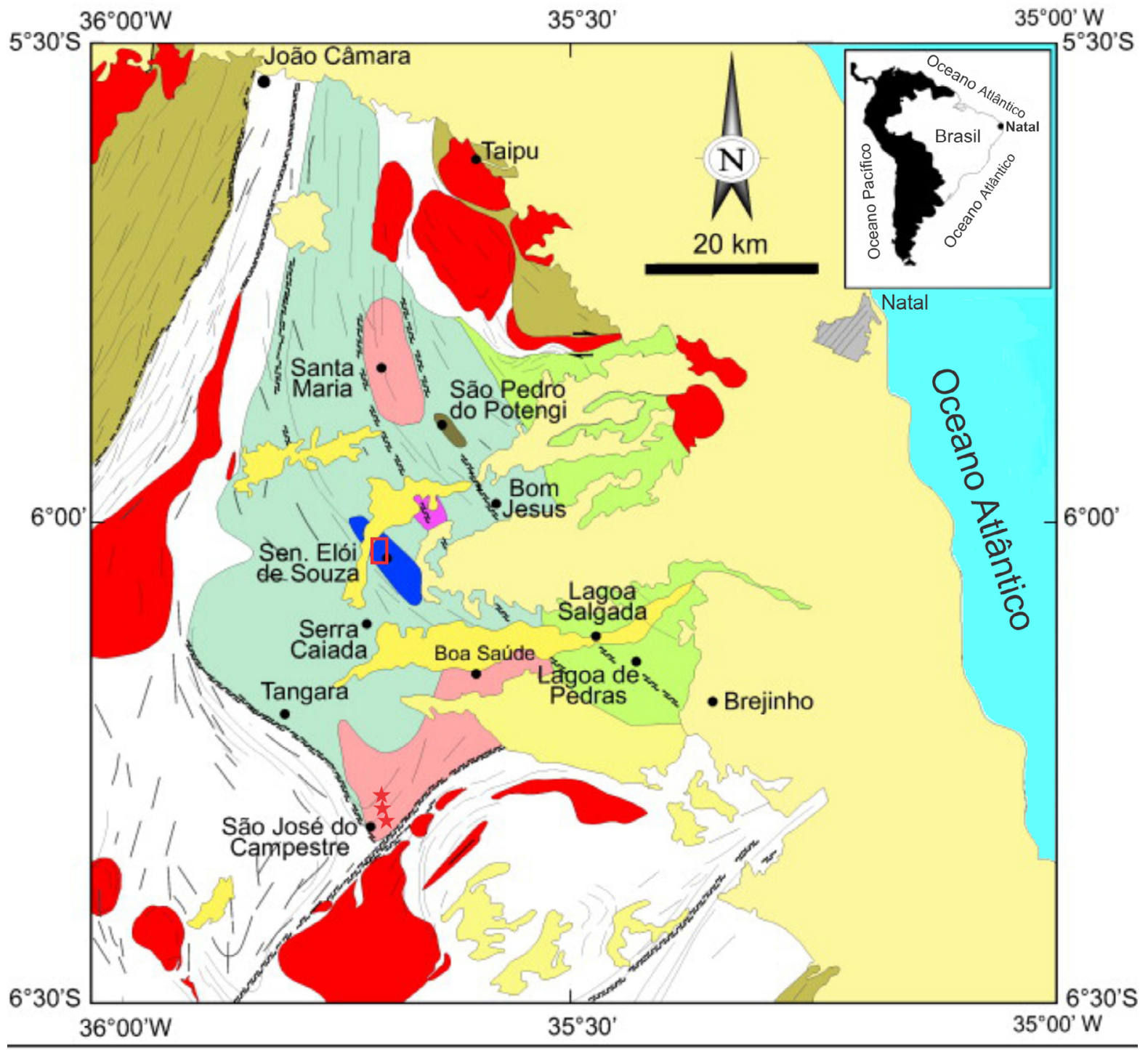

Cobertura cenozoica

Plutonismo Ediacarano (600 - $525 \mathrm{Ma})$

- Granitos, granodioritos, leucogranitos; subordinadamente gabros e doritos

\section{Grupo Seridó (Neoproterozoico)}

Micaxistos, mármores, paragnaisses, quartzitos

Terrenos paleoproterozoicos $(2,25$ - 2,15 Ga)

Granodioritos, tonalitos, granitos, gabros, quartzo dioritos

\# Trends estruturais, zonas de cisalhamento Área de estudo
Unidades arqueanas $(3,41-2,70 \mathrm{Ga})$

Complexo São José do Campestre Quartzo diorito a sienogranito $\quad 2,7 \mathrm{Ga}$

Complexo Senador Elói de Souza Anortosito, gabro $\quad 3,03 \mathrm{Ga}$

- Gnaisse São Pedro do Potengi Granodiorito

$3,12 \mathrm{Ga}$

Complexo Brejinho Gabro a granodiorito $3,33-3,18 \mathrm{Ga}$

Complexo Presidente Juscelino Principalmente monzogranitos; subordinadamente paragnaisses

Gnaisse Bom Jesus Gabro a tonalito $3,14 \mathrm{Ga}$

Figura 1. Mapa geológico da porção NE do Maciço São José do Campestre (compilado de Dantas et al., 2013), com localização do corpo estudado (realçado em vermelho) e amostras de clinopiroxenito (AD7.1B, AD9.1B e ES926Z1, realçadas por símbolos vermelhos). 
direção E-W, com solo argiloso e avermelhado. Nestes, foram encontrados blocos de apatita piroxenito, granada piroxenito e rochas ferruginosas. Outros corpos de direção N-S com canga laterítica e blocos de anfibólio piroxenito foram investigados em razão da ocorrência de anomalia magnética derivada de uma rocha ferruginosa que apresenta alta susceptibilidade magnética. No CSES, a sequência de rochas máficas e ultramáficas é caracterizada por pequenos corpos elípticos com largura entre 0,5 e $1,5 \mathrm{~km}$ e que estão em contato com rochas gnáissicas arqueanas, sendo classificadas como clinopiroxenitos e granulitos máficos a félsicos, com ocorrência subordinada de rochas calciossilicáticas. Apresentam texturas ígneas bem preservadas no centro do corpo e leve deformação nas bordas (Jesus, 2011). Datações U-Pb recentes em zircão nos carbonatitos indicam idade em $600 \pm 3 \mathrm{Ma}$ (Souza et al., 2018).

Corpos carbonatíticos associados com rochas ultramáficas no MSJC foram reportados por Teixeira (2012) e Cunha (2015), que descreveram corpos circulares ou semicirculares de direção preferencialmente NNW-SSE, compostos de granada piroxenito e calcita carbonatito com diferentes proporções de calcita, olivina, magnetita e granada. Assim como os corpos estudados nesta pesquisa, a ausência de feições de deformação e metamorfismo extensivo, além da relação de contato entre os corpos e as rochas encaixantes sugerindo truncamento, permitiram interpretar uma origem ígnea para as rochas carbonáticas.

Corpos de composição carbonática foram descritos no MSJC (Viegas, 2007; Figueiredo, 2012). Entretanto, estudos de isótopos $\delta^{13} \mathrm{C}$ e $\delta^{18} \mathrm{O}$ de Figueiredo (2012) caracterizam tais rochas como metacarbonatos de idade pré-cambriana, classificados em mármores calcíticos, mármores calcidolomíticos e mármores dolomíticos. Apesar das semelhanças composicionais, essas rochas se associam a granada paragnaisses e gnaisses calciossilicáticos, sendo sugerido por Souza (2018) um ambiente de bacia sedimentar depositada em um embasamento gnáissico de idade arqueana afetado por eventos tectono-deformacionais posteriores. Por outro lado, as rochas estudadas por Teixeira (2012) e Cunha (2015) fazem parte da tese de doutorado em desenvolvimento por um dos coautores deste trabalho (JAPC) envolvendo litoquímica, química mineral, gravimetria e magnetometria.

Trabalhos desenvolvidos por Silva (2017) descrevem blocos de composição carbonática com xenólitos de piroxenito (vide adiante) próximos ao município de Senador Elói de Souza, Rio Grande do Norte, associados a um corpo ultramáfico que trunca a foliação do embasamento gnáissico. Essas informações levou à investigação de outras feições que pudessem contribuir para a melhor compreensão das características dessas rochas e sua origem, tais como relações de contato, mineralogia e presença de feições deformacionais e metamórficas.

\section{MATERIAIS E MÉTODOS}

As análises petrográficas consistiram na descrição de 25 seções delgadas utilizando um microscópio de luz transmitida, modelo OLYMPUS BX41, em que 12 amostras foram selecionadas para a caracterização mineralógica e textural das rochas ultramáficas e carbonatíticas. As 13 amostras restantes fazem parte de um conjunto de rochas que compõem litologias aflorantes na região e relevantes para a compreensão do estudo, incluindo ortognaisses graníticos, rochas ferruginosas e leucogranitos.

Análises químicas de rocha total foram feitas no laboratório comercial ALS Mineral Labs, com determinação da concentração de óxidos (elementos maiores e menores), perda ao fogo e traços seguindo a metodologia ME-MS81d (ICP-MS) e a técnica analítica ME-ICP06 (ICP-AES), com erros analíticos na ordem de até $5 \%$ para óxidos e de $10-$ $15 \%$ para elementos traços. Os dados de química mineral foram obtidos por meio da análise em microssonda pela Universidade de Brasília (UnB) com utilização do equipamento JEOL-JXA-8230, que conta com cinco espectrômetros, aceleração de $15 \mathrm{kV}$, corrente de $10 \mathrm{nA}$, tempo de contagem de $10 \mathrm{~s}$ e feixe de elétrons de $1 \mu \mathrm{m}$ de diâmetro, sendo utilizados padrões sintéticos e naturais, com erros analíticos na ordem de $\pm 0,5-2 \%$ para $\mathrm{SiO}_{2}, \mathrm{Al}_{2} \mathrm{O}_{3}, \mathrm{FeO}$, $\mathrm{MgO}, \mathrm{MnO}, \mathrm{CaO}$ e $\mathrm{TiO}_{2}$, e de $0,4-0,5 \%$ para $\mathrm{Na}_{2} \mathrm{O}$ e $\mathrm{K}_{2} \mathrm{O}$.

Para investigar a geometria de um dos corpos ultramáficos, foi aplicado o método gravimétrico. $\mathrm{O}$ gravímetro utilizado para a aquisição dos dados é da marca Scintrex com modelo CG-G Autograv do Departamento de Geofísica da Universidade Federal do Rio Grande do Norte (UFRN). A aquisição foi realizada em um perfil N-S de $510 \mathrm{~m}$ com estações a cada $20 \mathrm{~m}$. As estações gravimétricas foram referenciadas à Rede Gravimétrica Fundamental do Brasil (RGFB) por meio da ocupação de uma estação gravimétrica base localizada no Departamento de Geofísica da UFRN, coordenadas $256829 \mathrm{E}$ e $9353995 \mathrm{~S}$, zona $25 \mathrm{M}$, cujo valor absoluto da gravidade $\mathrm{g}=978108,186 \mathrm{mGal}$ foi transferido para uma base secundária localizada na cidade de Santa Cruz, Rio Grande do Norte, nas coordenadas 829854 E e $9310888 \mathrm{~S}$, zona $24 \mathrm{M}$. O valor de $\mathrm{g}=978179,535 \mathrm{mGal}$ calculado para a estação secundária foi empregado como referência para o levantamento do perfil gravimétrico.

Os valores de anomalia Bouguer foram obtidos após a aplicação das correções de maré, deriva do instrumento, latitude, ar-livre e Bouguer, que foram realizadas no Excel 2016. Após as correções, os dados de gravimetria foram importados para o software Grav $2 \mathrm{dc}$ - desenvolvido por Cooper (2003) — da Escola de Geociências da Universidade de Witwatersrand e disponível de forma gratuita na internet. O Grav $2 \mathrm{dc}$ funciona por meio de modelagem direta, ou seja, por tentativa e erro aplicando-se o método de Talwani et al. (1959), que consiste na seleção das feições a 
serem modificadas que derivam no melhor ajuste das curvas. Dessa forma, o usuário pode modificar os valores de densidade, formato e profundidade das fontes de anomalia gravimétrica, até que o perfil gravimétrico calculado no programa se ajuste ao perfil gravimétrico observado.

\section{GEOLOGIA DE CAMPO}

O mapa geológico da Figura 2 ilustra a ocorrência dessas rochas e o possível truncamento da foliação do CSES, bem como as relações de contato entre clinopiroxenitos e carbonatitos, neste caso inferidas com base no modelo gravimétrico bidimensional. Clinopiroxenitos constituem o corpo ultramáfico, sendo maciços, de coloração cinza-escuro, textura equigranular média e variação composicional expressa por diferentes quantidades de calcita e escapolita, além de eventuais veios carbonáticos. Ocorrências de granada foram descritas em amostras afetadas por processos metamórficos resultando em porções avermelhadas nas rochas. Posteriormente, análises microscópicas revelaram a presença de cristais de plagioclásio nas porções metassomatizadas, e titanita como mineral acessório.

As rochas ferruginosas ocorrem na forma de blocos centimétricos e estão localizadas na borda do corpo ultramáfico, contribuindo para a formação de um solo mais

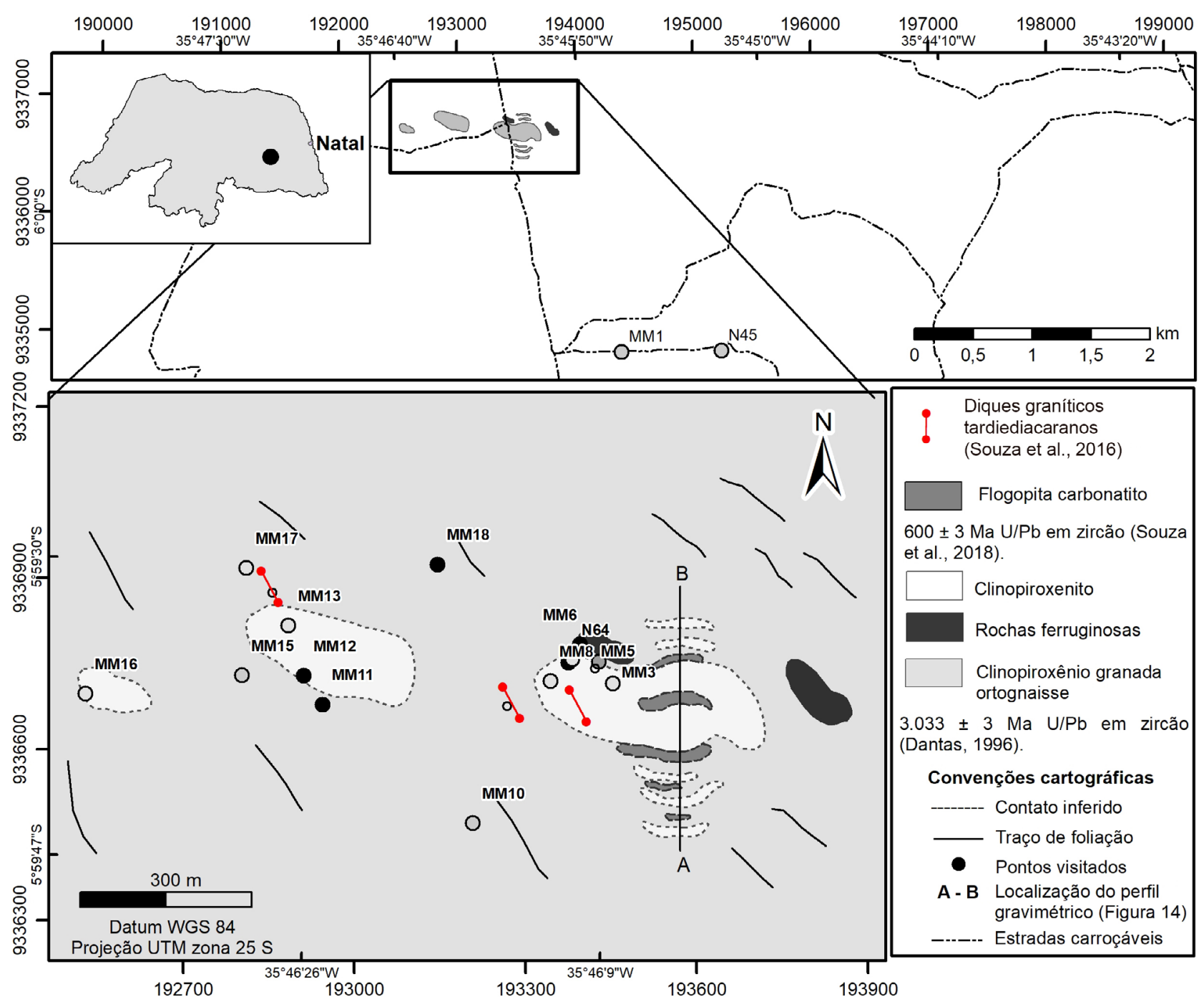

Figura 2. Mapa geológico simplificado dos corpos estudados com a localização dos pontos amostrados. O corpo principal, localizado na porção leste, é bordejado por pequenas lentes de carbonatitos conferindo uma feição semicircular no seu entorno, com base em mapeamento dos autores. 
avermelhado, contrastando com os solos de outros corpos piroxeníticos, que apresentam um solo tipicamente acinzentado. Mineralogicamente, são formadas por bandas ricas em quartzo alternadas por bandas ricas em magnetita.

As rochas ultramáficas que intrudem ortognaisses graníticos a tonalíticos do CSES e que abrangem os limites da área estudada foram classificadas como clinopiroxenitos. $\mathrm{Na}$ região, o corpo ultramáfico de direção E-W e comprimento aproximado de $500 \mathrm{~m}$ não aflora, sendo delimitado tanto pela diferença na tonalidade do solo quanto pela resposta do contraste de densidade a partir de dados gravimétricos. Assim, apesar da falta de rochas aflorantes, a presença de blocos centimétricos em sua superfície é responsável pela identificação e classificação de quatro litologias distintas com diferentes composições modais e minerais acessórios, comportando clinopiroxenito, carbonatito, leucogranito róseo e rochas ferruginosas (Figura 3). Além do corpo ultramáfico principal, outros dois corpos piroxeníticos são encontrados na proximidade, também marcados pela presença de blocos centimétricos de piroxenitos. Ocorrências de carbonatito, granito e rochas ferruginosas não foram observadas nesses corpos.

Os carbonatitos, por sua vez, são menos volumosos em superfície, mas compõem blocos de maior expressividade, atingindo até $70 \mathrm{~cm}$ em regiões localizadas no limite do corpo ultramáfico. São equigranulares, de granulação média a grossa, pouco deformados e classificados como calcita carbonatitos e flogopita carbonatitos. Análises microscópicas permitiram a identificação de processos de alteração que incluem serpentinização e oxidação de olivina e recristalização de calcita. Blocos de carbonatito com xenólitos de clinopiroxenito (N45) foram encontrados próximos ao corpo ultramáfico. Os xenólitos estão inclusos em flogopita carbonatito de textura grossa e possuem tamanhos variados e bordas arredondadas, podendo alcançar cerca de $20 \mathrm{~cm}$ de comprimento (Figuras 4A e 4B).
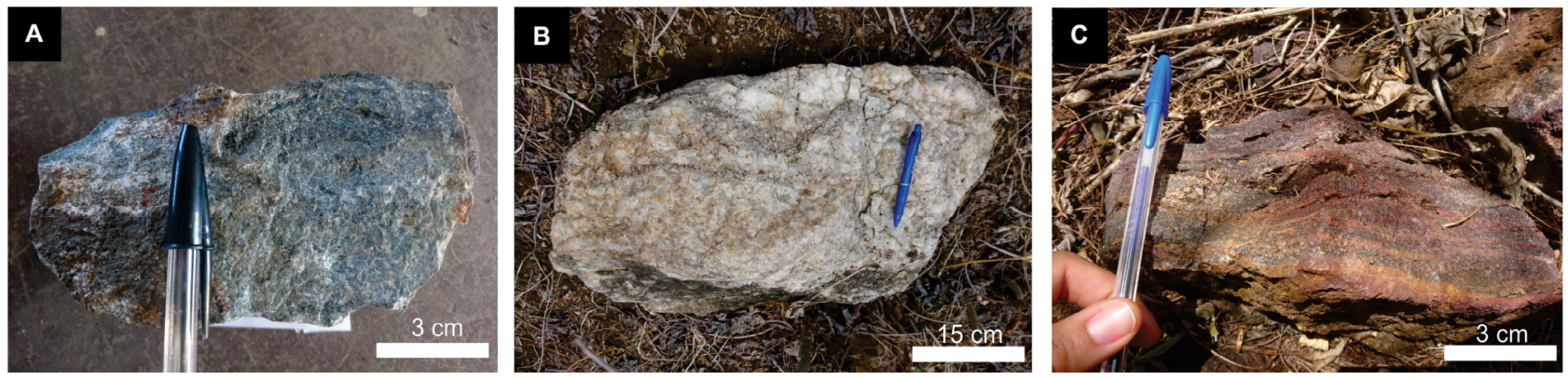

Figura 3. (A) Amostra de clinopiroxenito (MM3A - 193453/9336715, zona 25 S) com porções esbranquiçadas compostas de calcita e escapolita; (B) bloco de carbonatito (MM4 - 193429/9336753, zona 25 S); (C) amostra de rocha ferruginosa (MM6 - 193542/9336752, zona 25 S).

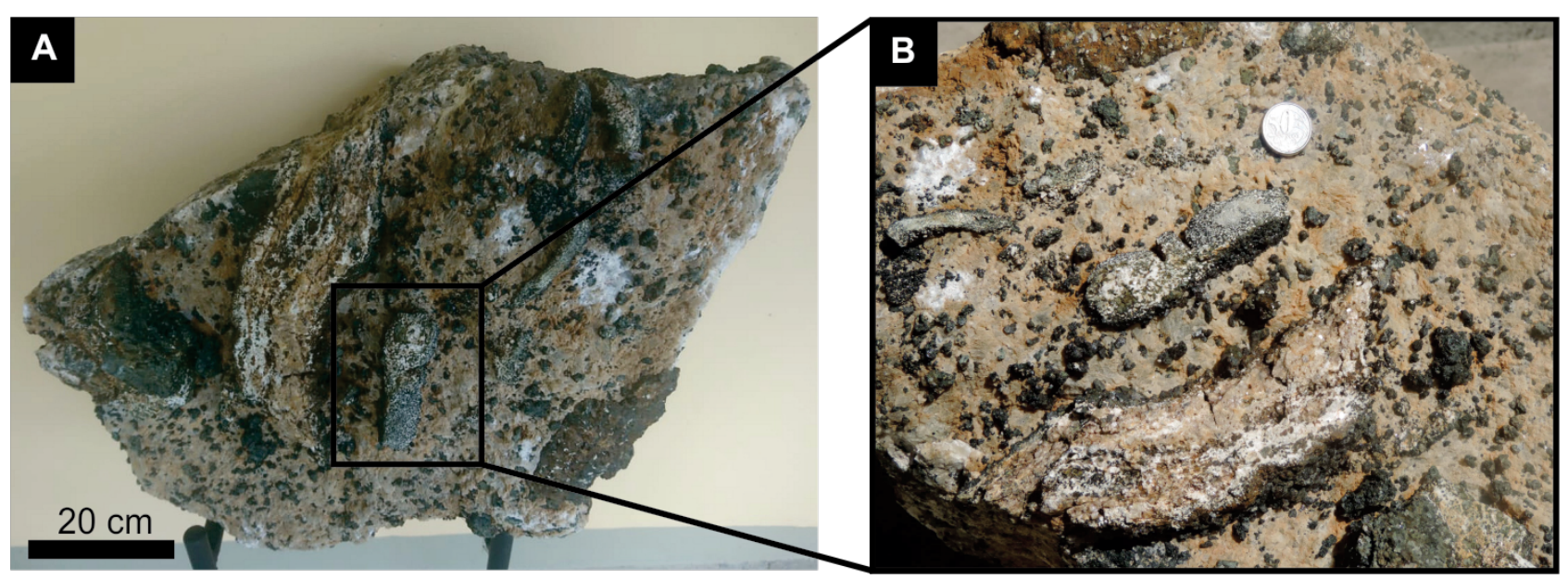

Figura 4. (A) Bloco de brecha magmática em que se destacam fragmentos de piroxenito imersos em matriz de carbonatito granoblástico (N45 - 195520/9334817, zona $25 \mathrm{~S}$ ); (B) detalhe mostrando fragmentos de piroxenito de tamanhos diferentes. A moeda de escala possui $2 \mathrm{~cm}$ de diâmetro. Crédito de fotografias: ZSS. 


\section{PETROGRAFIA}

As rochas ultramáficas, de acordo com Le Maitre (1989), são classificadas em clinopiroxenitos com mineralogia constituída essencialmente de hedenbergita $(90 \%)$, podendo conter pequenas quantidades de titanita e opacos (Figura 5A). Escapolita e calcita ocorrem em menor proporção e foram consideradas como formadas a partir de processos pós-magmáticos por meio da injeção de fluidos carbonáticos interpretados como derivados de processos metassomáticos.

O clinopiroxênio, do tipo rico em hedenbergita, possui tamanho médio de $1,0 \mathrm{~mm}$, textura em mosaico poligonal e simplectito envolvendo o plagioclásio (Figura 5B), podendo mostrar reações de uralitização localmente (Figura 5C). A escapolita é do tipo meionita e ocorre como cristais de tamanho médio $1,0 \mathrm{~mm}$, em contato irregular com a hedenbergita, apresentando formas de mosaicos poligonais em porções monominerálicas. A calcita ocorre em grãos com tamanhos de $0,5-1,0 \mathrm{~mm}$ e contato irregular com o clinopiroxênio. A titanita é tardia, normalmente associada ao piroxênio, com tamanho de $0,2-0,8 \mathrm{~mm}$ e hábito anédrico a euédrico. Observa-se cristalização de ilmenita na borda de alguns cristais (Figura 5D).

Amostras compostas essencialmente de hedenbergita, mas que contêm plagioclásio, grossulária, calcita e epídoto em quantidades significativas, foram interpretadas como porções do corpo ultramáfico afetadas por fluidos ricos em $\mathrm{CO}_{2} \mathrm{e} \mathrm{H}_{2} \mathrm{O}$, subsequentes à formação de textura de alta temperatura em mosaicos poligonais. Nesse contexto, os plagioclásios são subédricos e fortemente afetados por processos de sericitação; possuem contatos irregulares e tamanhos que variam de $0,5-2,0 \mathrm{~mm}$. A grossulária ocorre em amostras com maior quantidade de escapolita, calcita e plagioclásio, não sendo observada em clinopiroxenitos, em que o piroxênio é rico em hedenbergita. A grossulária é poiquilítica, mostrando contato irregular com hedenbergita
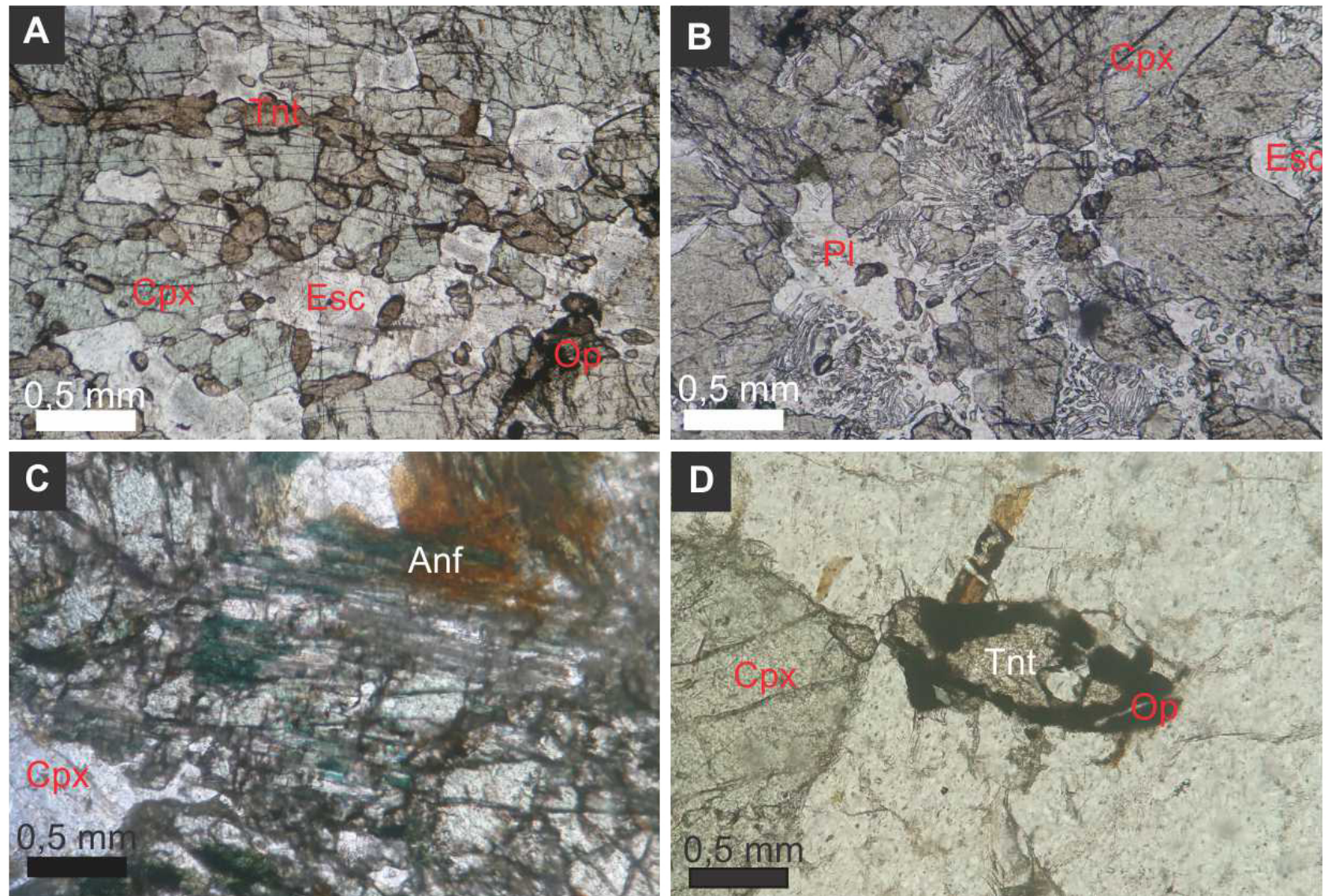

Tnt: titanita; Cpx: hedenbergita; Esc: escapolita; Op: ilmenita; PI: plagioclásio; Anf: actinolita.

Figura 5. Fotomicrografias dos clinopiroxenitos e suas principais associações minerais a nicóis paralelos. (A) Associação clinopiroxênio tipo hedenbergita + escapolita + titanita (N64D); (B) clinopiroxênio com contato irregular com escapolita (N64l) e ocorrência de plagioclásio; (C) actinolita formados de uralitização de clinopiroxênio; (D) titanita com borda parcial de ilmenita $(\mathrm{N} 64 \mathrm{H})$. 
e frequente transformação para esse piroxênio e escapolita. Dessa forma, interpretam-se efeitos de reações metassomáticas tardi-magmáticas envolvendo $\mathrm{CO}_{2}$, favorecendo a associação grossulária + Ca-plagioclásio + escapolita + hedenbergita (Deer et al., 2013).

Posteriormente, processos deformacionais atuantes no MSJC teriam sido responsáveis pela deformação na grossulária. Feições subsequentes de baixa temperatura se refletem em epidotização e sericitação de plagioclásio e actinolita a partir do piroxênio (Figura 5C).

Os carbonatitos são essencialmente cálcicos com granulação grossa a média, apresentando cristais de calcita de até 5,0 $\mathrm{mm}$. A calcita possui contato reto e textura poligonal
(Figura 6A), indicando que alcançou a estabilidade termal. Entre as fases acessórias, citam-se flogopita e diopsídio, as mais abundantes, além de quantidades menores de olivina (forsterita), granada (grossulária) e opacos.

A flogopita ocorre como cristais de 0,2-2,5 $\mathrm{mm}$ de tamanho e que são encontrados predominantemente em contato irregular com diopsídio e olivina (Figura 6B); o encurvamento da clivagem demonstra efeitos de deformação pós-magmática de baixa temperatura. A olivina apresenta tamanho médio de $2,0 \mathrm{~mm}$ e intenso processo de serpentinização, resultado da penetração de fluidos de baixa temperatura nas fraturas dos cristais (Figura 6C). A granada é observada de maneira pontual,
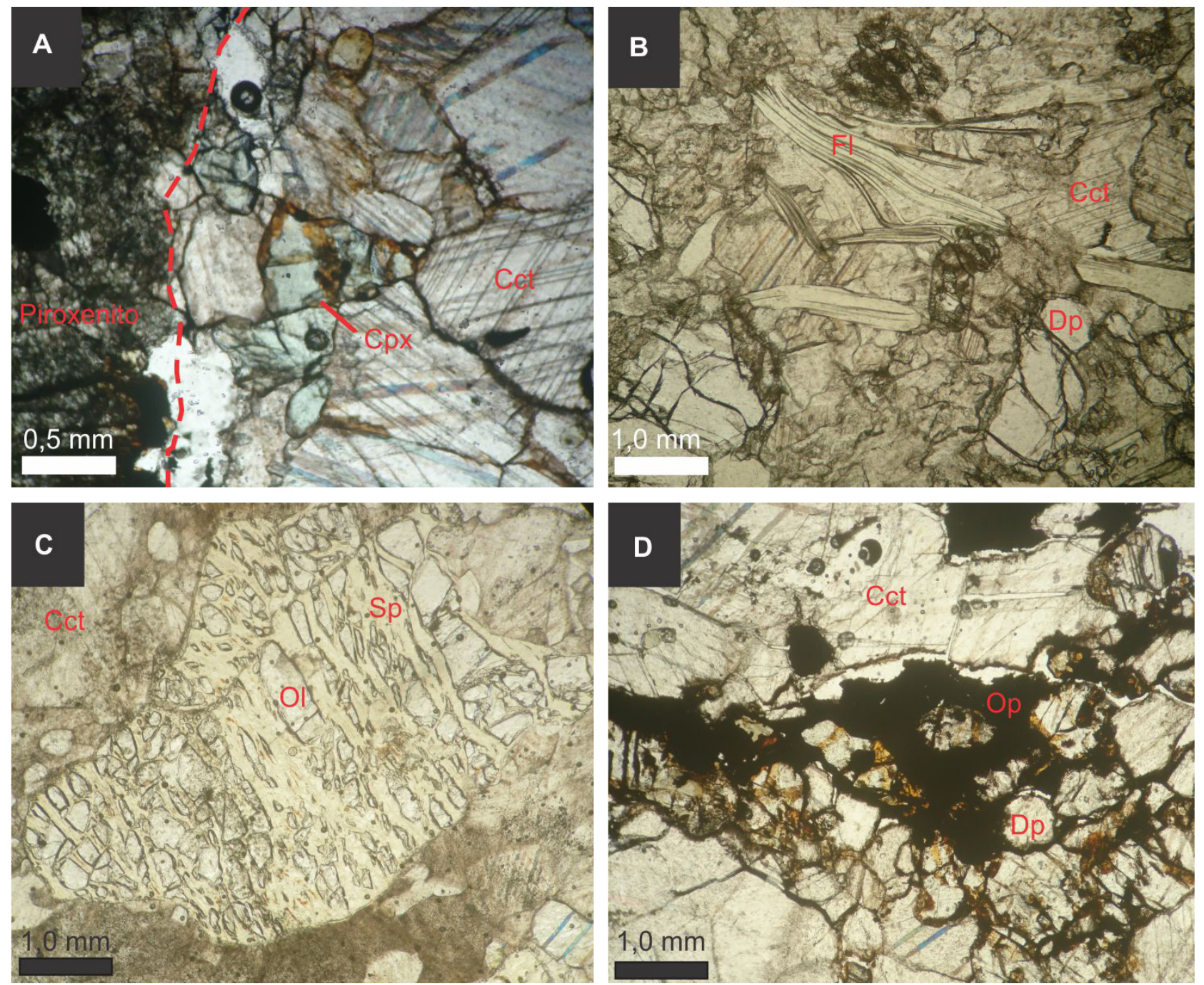

Cpx: clinopiroxênio; Cct: calcita; Fl: flogopita; Dp: diopsídio; Sp: serpentinizada; Ol: olivina; Op: opaco.

Figura 6. Fotomicrografias de carbonatitos em polarizadores descruzados. (A) Contato do clinopiroxenito à esquerda e flogopita carbonatito à direita (amostra MM4); (B) textura granoblástica média com predomínio de calcita sobre flogopita (amostra N45B); (C) cristal de olivina serpentinizada (amostra N45B); (D) opaco tardio intersticial formado a partir de alteração do diopsídio (amostra MM4). 
sendo reconhecida pelo relevo forte e positivo e seu caráter isotrópico; possui tamanho aproximado de $1,0 \mathrm{~mm}$ e é anédrica, ocorrendo em contato com a flogopita. Cristais de apatita apresentam contato irregular com calcita e atingem cerca de $1,0 \mathrm{~mm}$.

Processos de intensa oxidação envolvendo os carbonatitos são observados nas amostras coletadas no centro do corpo, apresentando um material de coloração amarronzada na borda da calcita, bem como alteração mineral em cristais de diopsídio, flogopita e olivina (Figura 6D). A formação de hidróxido de ferro a partir dessa alteração foi interpretada como resultado de processos intempéricos que convertem $\mathrm{Fe}^{2+}$ da olivina e do diopsídio em $\mathrm{Fe}^{3+}$ definindo faixas milimétricas intersticiais.

\section{QUÍMICA MINERAL}

Foram analisados clinopiroxênio, escapolita, plagioclásio e granada de clinopiroxenitos (MM2D e N64C) e flogopita, piroxênio e carbonato de flogopita carbonatito (N45C).

\section{Clinopiroxênio}

Neste estudo, foram realizadas 21 análises do clinopiroxênio em amostras de flogopita carbonatito (N45D), clinopiroxenito (N64C) e escapolita clinopiroxenito (MM2D). Os resultados analíticos estão na Tabela 1. Para a classificação química, foi usado o diagrama triangular de Morimoto (1988), no qual os resultados obtidos de piroxênios das rochas estudadas plotam no grupo primário QUAD e são da série diopsídio-hedenbergita, com componentes $\mathrm{En}_{50,6} \mathrm{Fs}_{0} \mathrm{Wo}_{49,4}$ para piroxênio de carbonatito e $\mathrm{En}_{24,4} \mathrm{Fs}_{25,6} \mathrm{Wo}_{49,7}$ para piroxênio de clinopiroxenito (Figura 7). O carbonatito apresenta piroxênio rico em diopsídio, enquanto o piroxênio do clinopiroxenito varia de Mg-diopsídio a hedenbergita. Valores empobrecidos em $\mathrm{Al}$ e $\mathrm{Na}$ (Tabela 1) indicam cristalização a baixas pressões (Deer et al., 2013).

\section{Flogopita}

Foram realizadas nove análises de flogopita (Tabela 2) do flogopita carbonatito, com fórmulas estruturais de 22 oxigênios (Deer et al., 2013) e assumindo todo o ferro como $\mathrm{Fe}^{2+}$.

A mica do carbonatito (N45D) possui composição homogênea, com valores muito baixos de Ti, Mn e Fe. A razão $\mathrm{Fe}_{\mathrm{t}} /\left(\mathrm{Fe}_{\mathrm{t}} / \mathrm{Mg}\right)$ próxima do zero e $\mathrm{Al}^{\mathrm{IV}}<2,4$ caracterizam uma mica do tipo flogopita (Figura 8).

\section{Plagioclásio}

Para o plagioclásio, duas análises foram realizadas em escapolita clinopiroxenito (MM2D), com os resultados analíticos na Tabela 3. Os dados obtidos foram calculados com base em oito oxigênios (Deer et al., 2013) e Fe assumido como $\mathrm{Fe}^{2+}$. Os dados químicos foram projetados no diagrama $\mathrm{Ab}-\mathrm{An}$-Or, em que é possível observar composições sódico-cálcicas marcadas por $\mathrm{An}_{31,6} \mathrm{Ab}_{67,5} \mathrm{Or}_{0,8}$, caracterizando-o como um plagioclásio reequilibrado em condições crustais.

\section{Escapolita}

A caracterização química da escapolita de piroxenitos foi baseada na análise de 12 cristais, sendo a fórmula estrutural calculada com base em 24 oxigênios e $\mathrm{Si}+\mathrm{Al}=12$ (Deer et al., 2013). A porcentagem do teor de meionita foi calculada segundo Deer et al. (2013), assumindo 100 (Ca $+\mathrm{Mg}+\mathrm{Fe}+\mathrm{Mn}+\mathrm{Ti}) /(\mathrm{Na}+\mathrm{K}+\mathrm{Ca}+\mathrm{Mg}+\mathrm{Fe}+\mathrm{Mn}$ + Ti). Os resultados analíticos são mostrados na Tabela 4. As escapolitas analisadas possuem composição $\mathrm{Me}_{55-76}$ e são alocadas no diagrama de Moazzen et al. (2009) e Teertstra et al. (1999), atestando uma composição próxima ao membro meionita (Figura 9). A composição química das escapolitas ricas em moléculas de meionita é sugestiva de cristalização em condições metassomáticas de alta temperatura (Deer et al., 2013).

\section{Granada}

A caracterização química da granada de piroxenito foi baseada na análise de três cristais, sendo a fórmula estrutural calculada com base em 12 oxigênios e oito cátions e determinação da razão $\mathrm{Fe}^{2+} / \mathrm{Fe}^{3+}$ por balanço de carga. A composição química da granada indica altos teores de $\mathrm{CaO}$, teores variáveis de $\mathrm{Al}_{2} \mathrm{O}_{3}$ e $\mathrm{FeO}$ e baixos teores de $\mathrm{MgO}$ e $\mathrm{MnO}$ (Tabela 5), com composição média $\mathrm{Alm}_{6,5} \mathrm{Gros}_{55,4} \mathrm{And}_{36,8}$.

Segundo Deer et al. (2013), a grossulária ocorre preferencialmente em dois tipos litológicos:

- rochas calcárias impuras que sofreram metamorfismo térmico e regional;

- rochas que não sofreram metassomatismo cálcico.

Ainda segundo esses autores, a grossulária também ocorre em zonas de metamorfismo de contato, apesar de a andradita ser a granada abundante nesse ambiente. Além disso, a andradita é uma granada típica de escarnitos metassomáticos, mas pode ser formada também a partir do metassomatismo de rochas ígneas de composição cálcica. Considerando o contexto das amostras estudadas, sugere-se a ação de fluidos metassomáticos ricos em $\mathrm{CaO}, \mathrm{CO}_{2}$ e $\mathrm{H}_{2} \mathrm{O}$ interagindo com magmas silicáticos magnesianos (clinopiroxenitos) e carbonatíticos, favorecendo o aumento da fugacidade de oxigênio e proporcionando a estabilização de granada rica em moléculas de grossulária e andradita. 


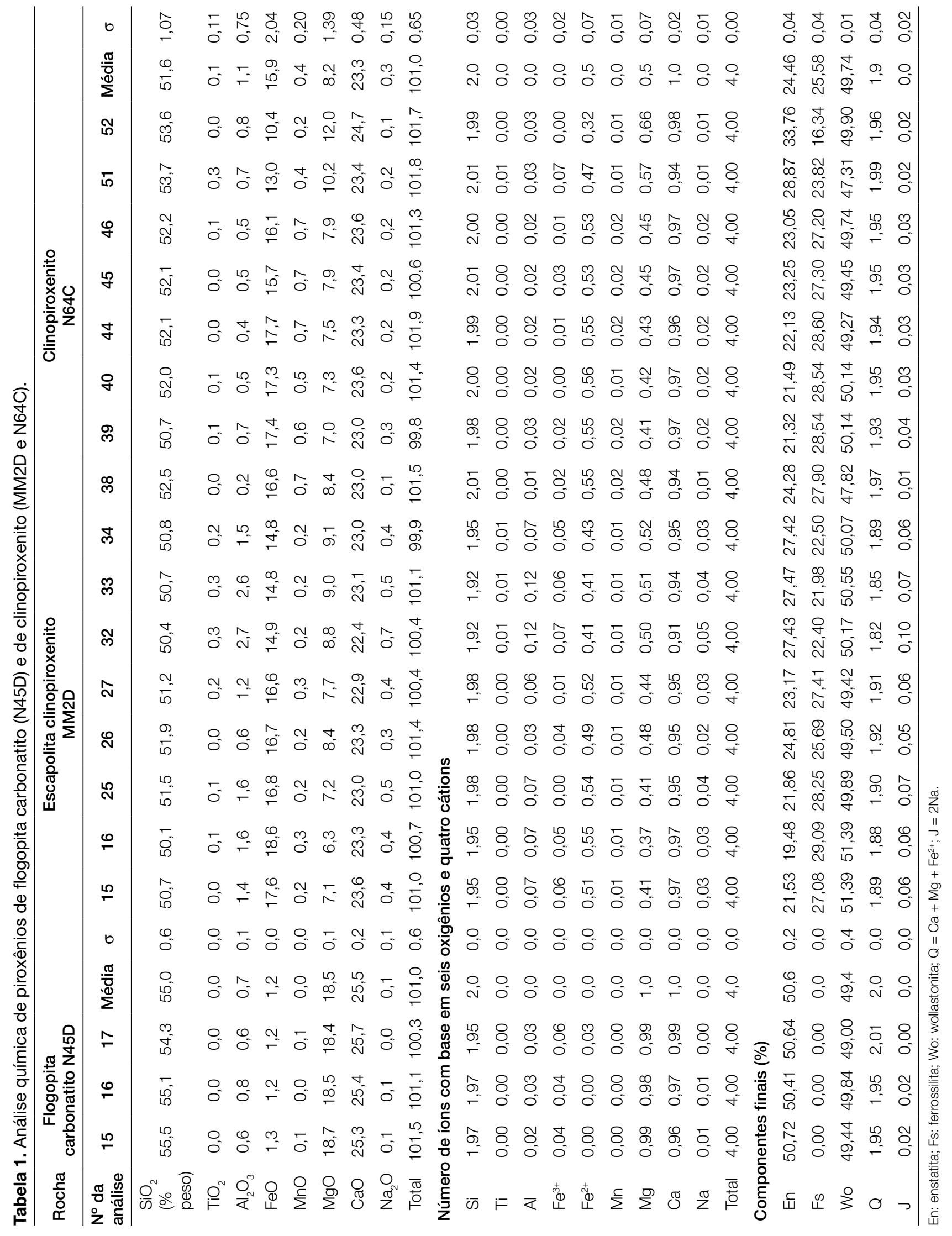




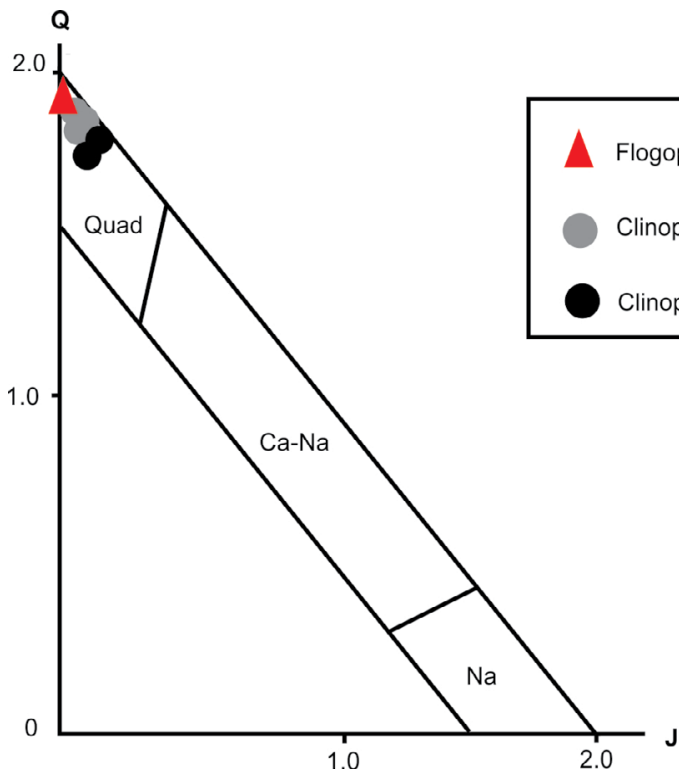

Wo: wollastonita; En: enstatita; Fs: ferrosilita.

Figura 7. Diagramas de classificação de piroxênios segundo Morimoto (1988). (A) Classificação (Ca-Mg-Fe clinopiroxênios) com wollastonita, enstatita e ferrosilita como membros finais; (B) diagrama de classificação $(Q-J) c o m ~ Q=C a+M g+$ $\mathrm{Fe}^{2+}$ e J $=2 \mathrm{Na}$.

Tabela 2. Análise química de flogopita de flogopita carbonatito (N45D).

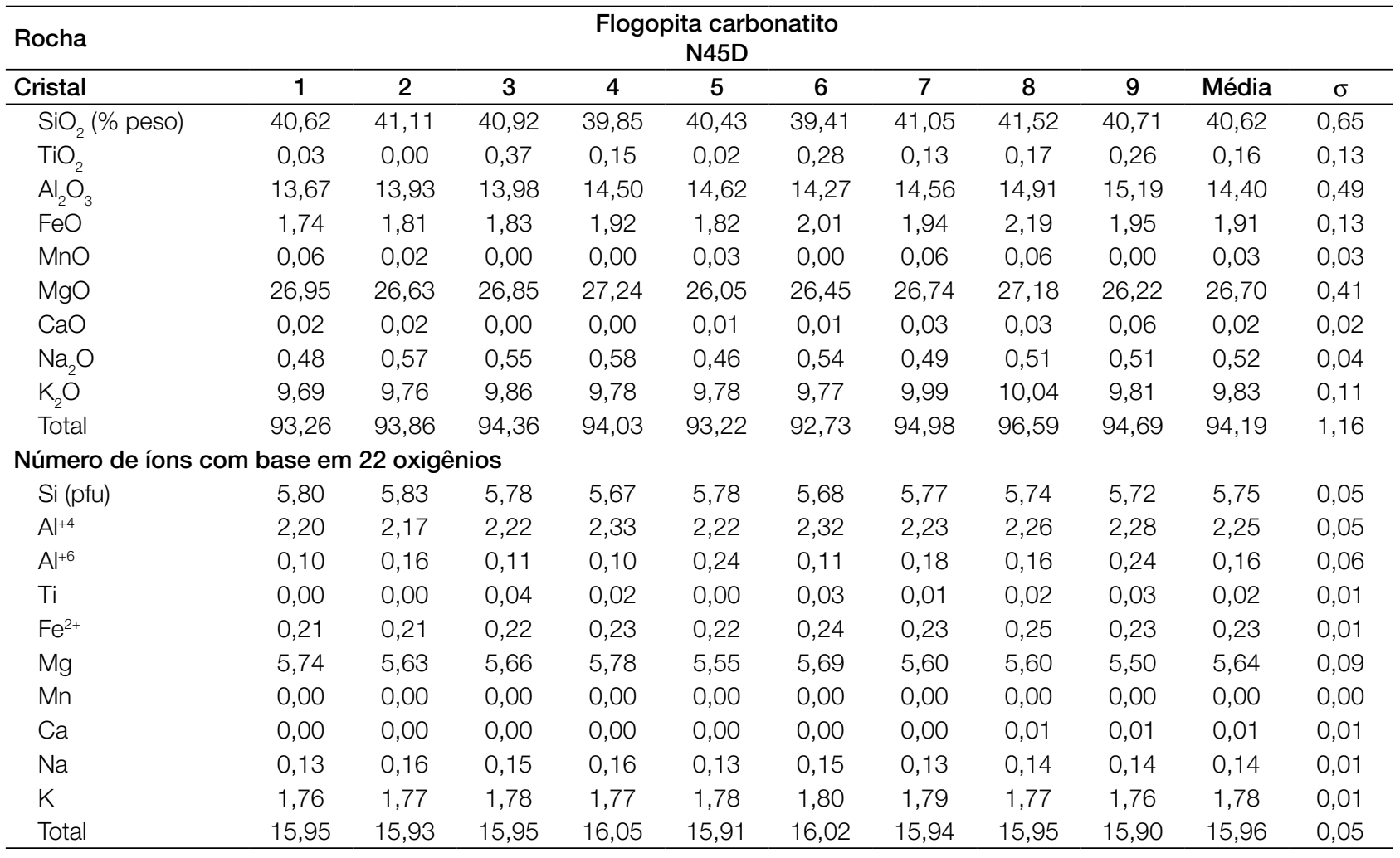




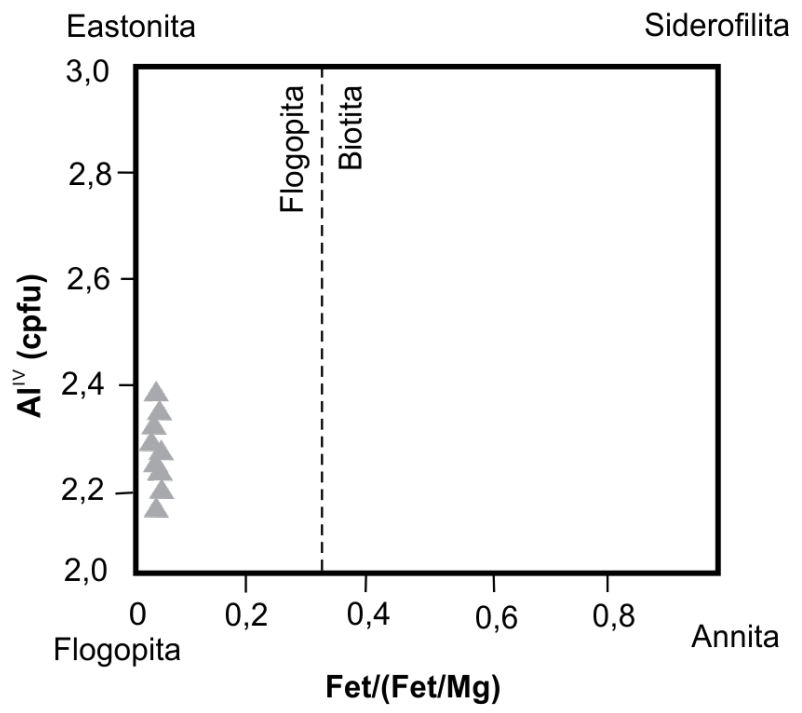

Figura 8. Classificação de micas de flogopita carbonatito (N45D) segundo Speer (1984).

Tabela 3. Análise química de plagioclásio de escapolita clinopiroxenito (MM2D).

\begin{tabular}{|c|c|c|c|c|}
\hline \multirow{2}{*}{$\begin{array}{l}\text { Rocha } \\
\text { Cristal }\end{array}$} & \multicolumn{4}{|c|}{$\begin{array}{l}\text { Escapolita clinopiroxenito } \\
\text { MM2D }\end{array}$} \\
\hline & 1 & 2 & Média & $\sigma$ \\
\hline $\mathrm{SiO}_{2}(\%$ peso) & 60,19 & 61,07 & 60,63 & 0,62 \\
\hline $\mathrm{TiO}_{2}$ & 0,00 & 0,12 & 0,06 & 0,08 \\
\hline $\mathrm{Al}_{2} \mathrm{O}_{3}$ & 24,29 & 24,20 & 24,25 & 0,07 \\
\hline $\mathrm{FeO}$ & 0,11 & 0,04 & 0,08 & 0,05 \\
\hline $\mathrm{MnO}$ & 0,05 & 0,03 & 0,04 & 0,02 \\
\hline $\mathrm{MgO}$ & 0,00 & 0,00 & 0,00 & 0,00 \\
\hline $\mathrm{CaO}$ & 6,86 & 6,82 & 6,84 & 0,03 \\
\hline $\mathrm{Na}_{2} \mathrm{O}$ & 8,06 & 8,09 & 8,07 & 0,02 \\
\hline $\mathrm{K}_{2} \mathrm{O}$ & 0,16 & 0,13 & 0,15 & 0,02 \\
\hline Total & 99,72 & 100,5 & 100,18 & 0,49 \\
\hline \multicolumn{5}{|c|}{ Número de íons com base em oito oxigênios } \\
\hline $\mathrm{Si}$ & 2,68 & 2,70 & 2,69 & 0,01 \\
\hline $\mathrm{Ti}$ & 0,00 & 0,00 & 0,00 & 0,00 \\
\hline $\mathrm{Al}$ & 1,28 & 1,26 & 1,27 & 0,01 \\
\hline $\mathrm{Fe}^{2+}$ & 0,00 & 0,00 & 0,00 & 0,00 \\
\hline $\mathrm{Mn}$ & 0,00 & 0,00 & 0,00 & 0,00 \\
\hline $\mathrm{Mg}$ & 0,00 & 0,00 & 0,00 & 0,00 \\
\hline $\mathrm{Ca}$ & 0,38 & 0,32 & 0,32 & 0,00 \\
\hline $\mathrm{Na}$ & 0,70 & 0,70 & 0,70 & 0,00 \\
\hline K & 0,00 & 0,00 & 0,00 & 0,00 \\
\hline Total & 5,00 & 4,9 & 4,95 & 0,00 \\
\hline \multicolumn{5}{|c|}{ Componentes finais (\%) } \\
\hline Anortita & 31,70 & 31,55 & 31,63 & 0,11 \\
\hline Albita & 67,41 & 67,73 & 67,57 & 0,23 \\
\hline Ortoclásio & 0,88 & 0,71 & 0,80 & 0,12 \\
\hline
\end{tabular}

\section{Carbonato}

A caracterização química dos carbonatos contou com a análise de sete cristais de flogopita carbonatito e as fórmulas estruturais foram calculadas com base em seis oxigênios e dois cátions. $\mathrm{O}$ carbonato é do tipo calcita praticamente pura, contendo apenas traços de $\mathrm{Mg}$ e $\mathrm{Fe}^{2+}$ (Tabela 6).

\section{LITOQUÍMICA}

Dados litoquímicos de carbonatitos e clinopiroxenitos (Tabela 7) se referem a nove amostras, sendo cinco cedidas por José Alexandre Paixão da Cunha (doutorando do Programa de Pós-Graduação em Geodinâmica e Geofísica da UFRN). As análises de carbonatito incluem o flogopita carbonatito N45D da região de Senador Elói de Souza, Rio Grande do Norte, e olivina carbonatitos AD7.4 e ES913Y coletados a leste de Tangará, Rio Grande do Norte. Essas rochas foram classificadas pelo diagrama triangular de Woolley e Kempe (1989) utilizando valores de $\mathrm{CaO}, \mathrm{MgO}$ e $\mathrm{FeO} *\left(\mathrm{Fe}_{2} \mathrm{O}_{3}+\right.$ $\mathrm{FeO}+\mathrm{MnO}$ ). As referidas amostras se classificam como Ca-carbonatito (N45D) e Mg-carbonatito (ES913Y e AD7.4). Em termos comparativos, carbonatitos da Província Ígnea do Alto Paranaíba (PIAP) com altas concentrações de ETRs foram utilizados para compor o espectro de alto ETR, representado por calcita carbonatitos de Serra Negra, Minas Gerais (Grasso, 2010), C1 de Catalão, Goiás (Gomide, 2015) e C1 de Salitre, Minas Gerais (Barbosa, 2009). Por outro lado, o espectro de baixos ETRs é representado por carbonatitos do Egito (Azer et al., 2010; Boskabadi et al., 2013) e de Gana (Attoh e Nude, 2008). Essas amostras, juntamente com os carbonatitos do MSJC, foram normalizadas ao condrito de Sun e McDonough (1989), sendo representados na Figura 10A.

O espectro de ETR (Figura 10A) dos carbonatitos mostra padrões paralelos e levemente inclinados $\left(\mathrm{La}_{\mathrm{N}} / \mathrm{Yb}_{\mathrm{N}}\right.$ $=8,9-49,8)$, enriquecimento de elementos terras raras leves (ETRL) em relação aos elementos terras raras pesadas (ETRP) e anomalia positiva de Eu na amostra AD7.4 e negativa nas amostras ES913Y e N45D. As amostras deste estudo estão inseridas na faixa que compreende carbonatitos empobrecidos em ETR, incluindo carbonatitos do Egito e de Gana, que apresentam razões $\left(\mathrm{La}_{\mathrm{N}} / \mathrm{Yb}_{\mathrm{N}}\right)$ médias de 2,8 e 46,2, respectivamente.

A assinatura espectral dos elementos incompatíveis é expressa nas Figuras 10B e 10C, em que se observa um padrão de comportamento similar entre o flogopita carbonatito (N45D) e olivina carbonatito (AD7.4 e ES913Y). Essas amostras, quando comparadas com carbonatitos da PIAP (Figura 10B) e do Egito e de Gana (Figura 10C), indicam que a assinatura dos elementos apresenta semelhança a partir do lantânio, com anomalias negativas de $\mathrm{Ce}$ e $\mathrm{Nd}$ em todos os litotipos. 
Tabela 4. Análise química de escapolita.

\begin{tabular}{|c|c|c|c|c|c|c|c|c|c|c|c|c|c|c|}
\hline \multicolumn{3}{|l|}{ Rocha/Amostra } & \multicolumn{3}{|c|}{$\begin{array}{c}\text { Clinopiroxenito } \\
\text { N64C }\end{array}$} & \multicolumn{9}{|c|}{$\begin{array}{c}\text { Escapolita clinopiroxenito } \\
\text { MM2D }\end{array}$} \\
\hline Cristal & 1 & 2 & 4 & 5 & 6 & 7 & 8 & 9 & 10 & 11 & 12 & 13 & Média & $\sigma$ \\
\hline $\mathrm{SiO}_{2}(\%$ peso) & 49,08 & 48,29 & 49,03 & 50,92 & 51,66 & 46,36 & 45,44 & 46,05 & 45,90 & 46,21 & 50,30 & 50,55 & 48,31 & 2,25 \\
\hline $\mathrm{TiO}_{2}$ & 0,00 & 0,00 & 0,00 & 0,09 & 0,00 & 0,02 & 0,00 & 0,00 & 0,01 & 0,00 & 0,00 & 0,00 & 0,01 & 0,03 \\
\hline $\mathrm{Al}_{2} \mathrm{O}_{3}$ & 25,73 & 25,92 & 25,97 & 25,24 & 24,46 & 27,21 & 26,20 & 26,61 & 26,75 & 26,65 & 24,61 & 24,57 & 25,82 & 0,93 \\
\hline $\mathrm{FeO}$ & 0,16 & 0,15 & 0,11 & 0,10 & 0,18 & 0,15 & 0,13 & 0,06 & 0,06 & 0,09 & 0,11 & 0,15 & 0,12 & 0,04 \\
\hline $\mathrm{CaO}$ & 15,83 & 16,52 & 15,50 & 14,41 & 13,80 & 17,92 & 18,31 & 18,75 & 18,54 & 18,22 & 13,93 & 13,82 & 16,30 & 2,00 \\
\hline $\mathrm{Na}_{2} \mathrm{O}$ & 4,46 & 3,99 & 4,51 & 5,16 & 5,47 & 3,33 & 2,82 & 3,14 & 3,10 & 3,24 & 5,59 & 5,96 & 4,23 & 1,12 \\
\hline $\mathrm{K}_{2} \mathrm{O}$ & 0,75 & 0,72 & 0,62 & 0,77 & 0,77 & 0,43 & 0,42 & 0,11 & 0,06 & 0,09 & 0,55 & 0,56 & 0,49 & 0,27 \\
\hline Total & 96,03 & 95,59 & 95,73 & 96,67 & 96,33 & 95,41 & 93,31 & 94,71 & 94,41 & 94,50 & 95,09 & 95,61 & 95,28 & 0,93 \\
\hline \multicolumn{15}{|c|}{ Número de íons com base em 24 oxigênios e $\mathrm{Si}+\mathrm{Al}=12$} \\
\hline Si (pfu) & 7,11 & 7,04 & 7,13 & 7,10 & 7,28 & 7,40 & 6,80 & 6,80 & 6,79 & 6,80 & 7,32 & 7,32 & 3,52 & 0,12 \\
\hline $\mathrm{Ti}$ & 0,00 & 0,00 & 0,00 & 0,00 & 0,00 & 0,00 & 0,00 & 0,00 & 0,00 & 0,00 & 0,00 & 0,00 & 0,00 & 0,00 \\
\hline $\mathrm{Al}$ & 4,39 & 4,45 & 4,18 & 4,43 & 4,25 & 4,13 & 4,70 & 4,63 & 4,66 & 4,64 & 4,22 & 4,19 & 2,96 & 0,14 \\
\hline $\mathrm{Fe}^{2+}$ & 0,01 & 0,02 & 0,10 & 0,01 & 0,01 & 0,02 & 0,02 & 0,00 & 0,01 & 0,01 & 0,01 & 0,02 & 0,01 & 0,00 \\
\hline $\mathrm{Mn}$ & 0,00 & 0,00 & 0,00 & 0,00 & 0,00 & 0,00 & 0,00 & 0,00 & 0,00 & 0,00 & 0,00 & 0,00 & 0,00 & 0,00 \\
\hline $\mathrm{Mg}$ & 0,00 & 0,00 & 0,02 & 0,00 & 0,00 & 0,00 & 0,01 & 0,00 & 0,00 & 0,00 & 0,00 & 0,00 & 0,00 & 0,00 \\
\hline $\mathrm{Ca}$ & 2,46 & 2,58 & 2,56 & 2,40 & 2,21 & 2,12 & 2,81 & 2,97 & 2,94 & 2,88 & 2,17 & 2,14 & 2,55 & 0,34 \\
\hline $\mathrm{Na}$ & 1,25 & 1,13 & 1,32 & 1,26 & 1,43 & 1,52 & 0,94 & 0,90 & 0,89 & 0,93 & 1,58 & 1,67 & 1,19 & 0,30 \\
\hline $\mathrm{K}$ & 0,14 & 0,13 & 0,16 & 0,11 & 0,14 & 0,14 & 0,08 & 0,02 & 0,01 & 0,02 & 0,10 & 0,10 & 0,09 & 0,05 \\
\hline Total & 15,36 & 15,35 & 15,47 & 15,31 & 15,32 & 15,33 & 15,36 & 15,32 & 15,3 & 15,28 & 15,40 & 15,44 & 15,35 & 0,06 \\
\hline Z & 11,5 & 11,49 & 11,31 & 11,53 & 11,53 & 11,53 & 11,50 & 11,43 & 11,45 & 11,44 & 11,51 & 11,51 & 11,48 & 0,06 \\
\hline$x$ & 3,86 & 3,86 & 4,16 & 3,78 & 3,79 & 3,80 & 3,86 & 3,89 & 3,85 & 3,84 & 3,89 & 3,93 & 3,88 & 0,10 \\
\hline$\% \mathrm{Me}$ & 64,26 & 67,50 & 63,80 & 58,74 & 56,62 & 73,57 & 76,81 & 76,49 & 76,68 & 75,48 & 56,70 & 55,09 & 66,81 & 8,72 \\
\hline
\end{tabular}

$\% \mathrm{Me}: 100(\mathrm{Ca}+\mathrm{Mg}+\mathrm{Fe}+\mathrm{Mn}+\mathrm{Ti}) /(\mathrm{Na}+\mathrm{K}+\mathrm{Ca}+\mathrm{Mg}+\mathrm{Fe}+\mathrm{Mn}+\mathrm{Ti})$.

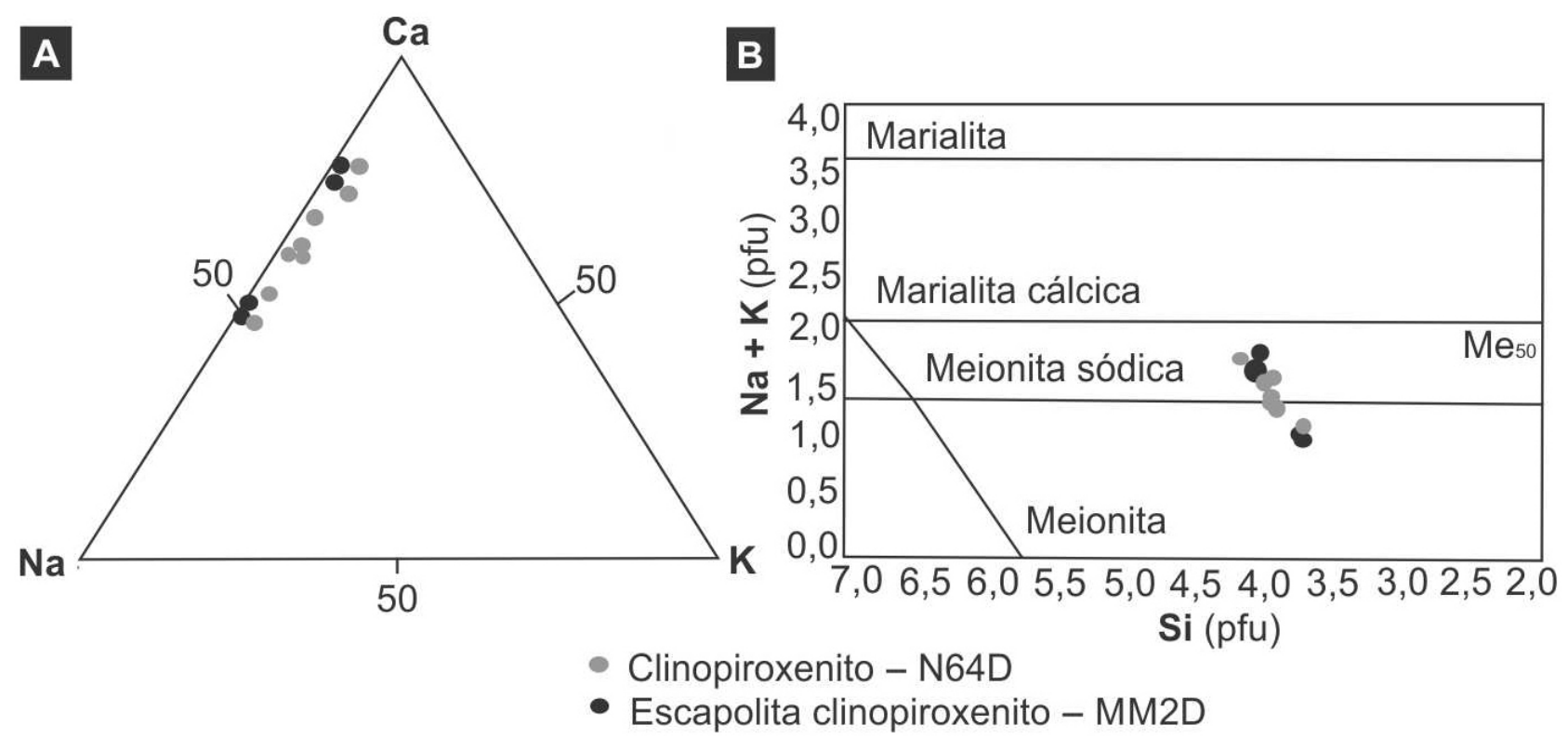

Figura 9. (A) Classificação de escapolita, segundo Moazzen et al. (2009), das amostras MM2D e N64C; (B) diagrama de classificação segundo Teertstra et al. (1999). 
Tabela 5. Análise química de granada de escapolita clinopiroxenito (MM2D).

\begin{tabular}{lccccc}
\hline Cristal & $\mathbf{1}$ & $\mathbf{2}$ & $\mathbf{3}$ & Média & $\sigma$ \\
\hline $\mathrm{SiO}_{2}$ (\% peso) & 38,74 & 38,25 & 37,94 & 38,31 & 0,40 \\
$\mathrm{TiO}_{2}$ & 0,26 & 0,42 & 0,30 & 0,32 & 0,08 \\
$\mathrm{Al}_{2} \mathrm{O}_{3}$ & 14,08 & 11,18 & 11,86 & 12,37 & 1,52 \\
$\mathrm{Cr}_{2} \mathrm{O}_{3}$ & 0,13 & 0,02 & 0,01 & 0,05 & 0,06 \\
$\mathrm{FeO}$ & 12,26 & 15,63 & 15,77 & 14,55 & 1,99 \\
$\mathrm{MnO}$ & 0,28 & 0,35 & 0,22 & 0,28 & 0,07 \\
$\mathrm{MgO}$ & 0,14 & 0,12 & 0,13 & 0,13 & 0,01 \\
$\mathrm{CaO}$ & 33,52 & 33,34 & 32,92 & 33,26 & 0,31 \\
Total & 99,40 & 99,30 & 99,13 & 99,28 & 0,14
\end{tabular}

Número de íons com base em 12 oxigênios e oito cátions

\begin{tabular}{lccccc}
$\mathrm{Si}$ (pfu) & 3,03 & 3,03 & 3,01 & 3,02 & 0,01 \\
$\mathrm{Ti}$ & 0,02 & 0,02 & 0,02 & 0,02 & 0,01 \\
$\mathrm{Al}$ & 1,30 & 1,04 & 1,11 & 1,15 & 0,13 \\
$\mathrm{Cr}$ & 0,01 & 0,00 & 0,00 & 0,00 & 0,00 \\
$\mathrm{Fe}^{3+}$ & 0,60 & 0,85 & 0,85 & 0,76 & 0,14 \\
$\mathrm{Fe}^{2+}$ & 0,20 & 0,19 & 0,20 & 0,20 & 0,01 \\
$\mathrm{Mn}$ & 0,02 & 0,02 & 0,01 & 0,02 & 0,00 \\
$\mathrm{Mg}$ & 0,02 & 0,01 & 0,02 & 0,02 & 0,00 \\
$\mathrm{Ca}$ & 2,81 & 2,83 & 2,79 & 2,81 & 0,02 \\
Total & 7,99 & 7,99 & 8,01 & 7,99 & 0,00 \\
Componentes finais (\%) & & & & \\
Almandina & 6,61 & 6,18 & 6,58 & 6,46 & 0,24 \\
Espessatina & 0,62 & 0,76 & 0,48 & 0,62 & 0,14 \\
Piropo & 0,53 & 0,45 & 0,51 & 0,50 & 0,04 \\
Grossulária & 62,80 & 51,10 & 52,38 & 55,43 & 6,42 \\
Andradita & 29,06 & 41,44 & 40,01 & 36,84 & 6,78 \\
Uvarovita & 0,38 & 0,07 & 0,04 & 0,16 & 0,19 \\
\hline
\end{tabular}

A Figura 11 representa um diagrama de Samoilov (1991), em que os carbonatitos do MSJC plotam no campo de rochas sedimentares e metamórficas, a exemplo de carbonatitos da Península do Sinai (Egito) e do Dahomeyide de Gana, enquanto os carbonatitos da PIAP plotam no campo dos carbonatitos ígneos.

Os dados litoquímicos de clinopiroxenitos incluem três amostras do CSES (N45C, N64C e N64D) e três amostras da área a leste de Tangará, Rio Grande do Norte (ES926Z9, AD7.1B e AD9.1B) (Figura 1). Os clinopiroxenitos apresentam teores de $\mathrm{CaO}$ que variam entre $20 \mathrm{e}$ $25 \%, 4-16 \%$ de $\mathrm{Fe}_{2} \mathrm{O}_{3}, 8-13 \%$ de $\mathrm{MgO}$ e $\mathrm{Mg} \#$ entre 0,43 e 0,84 . A natureza do material parental identificada a partir da afinidade geoquímica sugerida pelo diagrama AFM (Irvine e Baragar, 1971) indica tendência de enriquecimento em ferro (Figura 12A). Diagramas de variação tipo Harker mostram que os clinopiroxenitos são mais ricos em $\mathrm{Al}_{2} \mathrm{O}_{3}$ e $\mathrm{MgO}$, possuindo $\mathrm{CaO}$ estável durante a evolução magmática; carbonatitos compõem um grupo distinto, com valores baixos de $\mathrm{Al}_{2} \mathrm{O}_{3}$, moderados de $\mathrm{MgO}$ e altos de $\mathrm{CaO}$ (Figuras 12a a 12D).

Os clinopiroxenitos possuem baixo conteúdo de ETR, com $\Sigma$ ETR entre 24,15 e 147,42 ppm, Y (11 - 88,2 ppm), $\mathrm{Zr}(24-150 \mathrm{ppm}), \mathrm{V}(40-96 \mathrm{ppm}), \mathrm{U}(0,34-3,86 \mathrm{ppm})$ e Th $(0,77-15,25 \mathrm{ppm})$. Quando normalizados com o condrito (Sun e McDonough, 1989), apresentam padrões pouco fracionados com razões $\mathrm{La}_{\mathrm{N}} / \mathrm{Yb}_{\mathrm{N}}$ entre 1,5 e 8,6. Anomalias negativas de európio ocorrem em todas as amostras (Figura 13A), o que sugere cristalização de plagioclásio ou sua retenção na fonte. Quando normalizados ao manto primitivo, os elementos incompatíveis apresentam leve enriquecimento em relação aos mais

Tabela 6. Composição química de carbonato de flogopita carbonatito (N45D).

\begin{tabular}{cccccccccc}
\hline Cristal & $\mathbf{1}$ & $\mathbf{2}$ & $\mathbf{3}$ & $\mathbf{4}$ & $\mathbf{5}$ & $\mathbf{6}$ & $\mathbf{7}$ & Média & $\sigma$ \\
\hline $\mathrm{FeO}$ & 0,07 & 0,20 & 0,23 & 0,20 & 0,18 & 0,40 & 0,12 & 0,20 & 0,10 \\
$\mathrm{MnO}$ & 0,00 & 0,17 & 0,05 & 0,01 & 0,01 & 0,00 & 0,05 & 0,04 & 0,06 \\
$\mathrm{MgO}$ & 0,04 & 1,46 & 1,90 & 1,71 & 1,42 & 4,20 & 0,81 & 1,65 & 1,29 \\
$\mathrm{CaO}$ & 55,74 & 57,17 & 53,08 & 53,42 & 53,72 & 52,07 & 54,83 & 54,29 & 1,74 \\
$\mathrm{Na}$ & 0,01 & 0,00 & 0,00 & 0,00 & 0,00 & 0,01 & 0,03 & 0,01 & 0,01 \\
$\mathrm{Total}$ & 55,86 & 59,00 & 55,25 & 55,34 & 55,33 & 56,69 & 55,84 & 56,19 & 1,34 \\
$\mathrm{Número} \mathrm{de} \mathrm{íons} \mathrm{com} \mathrm{base} \mathrm{em} \mathrm{seis} \mathrm{oxigênios} \mathrm{e} \mathrm{dois} \mathrm{cátions}$ & & & & & & \\
$\mathrm{Fe}^{2+}$ & 0,00 & 0,00 & 0,00 & 0,00 & 0,00 & 0,00 & 0,00 & 0,00 & 0,00 \\
$\mathrm{Mn}$ & 0,00 & 0,00 & 0,00 & 0,00 & 0,00 & 0,00 & 0,00 & 0,00 & 0,00 \\
$\mathrm{Mg}$ & 0,00 & 0,07 & 0,09 & 0,09 & 0,07 & 0,20 & 0,04 & 0,08 & 0,06 \\
$\mathrm{Ca}$ & 1,99 & 1,99 & 1,89 & 1,90 & 1,92 & 1,78 & 1,95 & 1,91 & 0,07 \\
$\mathrm{Na}$ & 0,00 & 0,00 & 0,00 & 0,00 & 0,00 & 0,00 & 0,00 & 0,00 & 0,00 \\
$\mathrm{Total}$ & 1,99 & 1,99 & 1,98 & 1,99 & 1,99 & 1,99 & 1,99 & 1,99 & 0,80 \\
\hline
\end{tabular}


Tabela 7. Composição de rocha total de clinopiroxenitos e carbonatitos do Maciço São José do Campestre.

\begin{tabular}{|c|c|c|c|c|c|c|c|c|c|}
\hline \multirow[b]{2}{*}{ Amostra } & \multicolumn{3}{|c|}{ Carbonatito } & \multicolumn{6}{|c|}{ Piroxenito } \\
\hline & AD7.4 & ES913Y & N45D & $\mathrm{N} 45 \mathrm{C}$ & N64C & N64D & AD7.1B & AD9.1B & ES926Z1 \\
\hline \multicolumn{10}{|c|}{ Óxidos (\% peso) } \\
\hline $\mathrm{SiO}_{2}$ & 6,87 & 11,4 & 11,05 & 51,9 & 46,9 & 48,6 & 50,6 & 45,9 & 51,4 \\
\hline $\mathrm{TiO}_{2}$ & 0,15 & 0,04 & 0,04 & 0,1 & 0,1 & 0,44 & 0,29 & 0,38 & 0,27 \\
\hline $\mathrm{Al} 2 \mathrm{O}_{3}$ & 1,17 & 0,52 & 1,49 & 3,38 & 3,49 & 5,86 & 3,55 & 9,36 & 2,83 \\
\hline $\mathrm{Fe}_{2} \mathrm{O}_{3 \mathrm{t}}$ & 11,25 & 2,56 & 0,76 & 10,8 & 16,05 & 13,6 & 4,93 & 8,96 & 8,99 \\
\hline $\mathrm{MnO}$ & 0,56 & 0,27 & 0,06 & 0,28 & 0,5 & 0,47 & 0,37 & 1,09 & 0,86 \\
\hline $\mathrm{MgO}$ & 6,95 & 11,9 & 5,54 & 9,29 & 6,17 & 6,44 & 13,8 & 8,19 & 10,75 \\
\hline $\mathrm{CaO}$ & 40,9 & 39,4 & 43,9 & 20,7 & 21,1 & 22,2 & 24,6 & 25 & 21,7 \\
\hline $\mathrm{Na}_{2} \mathrm{O}$ & $<0.01$ & $<0.01$ & 0,1 & 0,91 & 0,61 & 0,85 & 0,18 & 0,24 & 0,48 \\
\hline $\mathrm{K}_{2} \mathrm{O}$ & $<0.01$ & 0,01 & 0,74 & 0,15 & 0,1 & 0,11 & 0,27 & 0,5 & 0,04 \\
\hline $\mathrm{P}_{2} \mathrm{O} 5$ & 0,02 & 0,01 & 0,01 & 0,02 & 0,02 & 0,06 & 0,06 & 0,12 & 0,05 \\
\hline PF & 33,4 & 34,6 & 34,6 & 1,12 & 3,68 & 2,02 & 1,44 & 0,79 & 0,45 \\
\hline Total & 101,28 & 100,72 & 98,36 & 98,66 & 98,73 & 100,67 & 100,1 & 100,55 & 97,84 \\
\hline Mg\# & 0,55 & 0,90 & 0,93 & 0,63 & 0,43 & 0,48 & 0,84 & 0,64 & 0,70 \\
\hline \multicolumn{10}{|c|}{ Elementos traços (ppm) } \\
\hline $\mathrm{Ba}$ & 86,1 & 54,1 & 376 & 75 & 95,4 & 48,8 & 102,5 & 172 & 210 \\
\hline Cs & 0,01 & 0,11 & 1,87 & 0,74 & 0,11 & 0,12 & 0,93 & 0,76 & 0,99 \\
\hline $\mathrm{Ga}$ & 4 & 5,5 & 2,8 & 10,4 & 8,2 & 9,9 & 8,5 & 14,2 & 5,8 \\
\hline $\mathrm{Hf}$ & 0,3 & 0,5 & 0,7 & 1,5 & 0,7 & 2,1 & 1,8 & 5,2 & 0,9 \\
\hline $\mathrm{Nb}$ & 1 & 0,5 & 2,7 & 5,6 & 3,4 & 6,1 & 2,8 & 7,2 & 3,9 \\
\hline $\mathrm{Rb}$ & 0,4 & 0,4 & 36,5 & 6,1 & 2 & 2,3 & 18 & 41,2 & 2,2 \\
\hline $\mathrm{Sr}$ & 75,6 & 75 & 338 & 112,5 & 77,4 & 119,5 & 83,5 & 58,5 & 48 \\
\hline $\mathrm{Ta}$ & 0,3 & 0,3 & 0,5 & 0,6 & 0,4 & 0,3 & 0,9 & 0,8 & 0,2 \\
\hline Th & 0,05 & $<0.05$ & 1,25 & 2,7 & 0,77 & 4,8 & 2,25 & 15,25 & 1,58 \\
\hline$U$ & $<0.05$ & 1,08 & 0,45 & 0,87 & 0,34 & 2,97 & 1,19 & 3,86 & 1,4 \\
\hline V & 35 & 25 & 15 & 40 & 85 & 96 & 58 & 70 & 48 \\
\hline Y & 1,4 & 1,5 & 8,1 & 20 & 8,8 & 9,6 & 20,7 & 88,2 & 11 \\
\hline $\mathrm{Zr}$ & 12 & 14 & 15 & 37 & 24 & 70 & 56 & 150 & 27 \\
\hline \multicolumn{10}{|c|}{ Elementos terras raras (ppm) } \\
\hline $\mathrm{La}$ & 4,4 & 1,7 & 18,7 & 27,9 & 3,4 & 4,6 & 9 & 25,1 & 4,1 \\
\hline $\mathrm{Ce}$ & 4,6 & 3,1 & 31,4 & 62,8 & 8 & 11 & 21,3 & 44,6 & 7,4 \\
\hline $\operatorname{Pr}$ & 0,44 & 0,31 & 2,6 & 6,55 & 1 & 1,44 & 3,01 & 4,73 & 1,01 \\
\hline $\mathrm{Nd}$ & 1,7 & 1,1 & 9,2 & 23,8 & 5 & 6,8 & 11,5 & 17,6 & 4,3 \\
\hline Sm & 0,2 & 0,31 & 1,72 & 4,47 & 1,19 & 1,65 & 2,33 & 5,12 & 1,05 \\
\hline $\mathrm{Eu}$ & 0,1 & 0,03 & 0,39 & 0,52 & 0,26 & 0,48 & 0,45 & 1,14 & 0,31 \\
\hline $\mathrm{Gd}$ & 0,21 & 0,16 & 1,44 & 3,35 & 1,29 & 1,61 & 2,65 & 8,38 & 1,33 \\
\hline $\mathrm{Tb}$ & 0,02 & 0,03 & 0,21 & 0,55 & 0,22 & 0,25 & 0,43 & 1,68 & 0,25 \\
\hline Dy & 0,17 & 0,19 & 1,09 & 3,14 & 1,3 & 1,59 & 2,93 & 12,1 & 1,54 \\
\hline $\mathrm{Ho}$ & 0,03 & 0,04 & 0,21 & 0,59 & 0,26 & 0,33 & 0,67 & 2,99 & 0,33 \\
\hline Er & 0,05 & 0,05 & 0,55 & 1,61 & 0,79 & 0,79 & 1,96 & 9,44 & 0,94 \\
\hline $\mathrm{Tm}$ & 0,03 & 0,04 & 0,09 & 0,31 & 0,12 & 0,11 & 0,34 & 1,63 & 0,14 \\
\hline $\mathrm{Yb}$ & 0,06 & 0,13 & 0,49 & 2,21 & 1,09 & 1,3 & 2,25 & 11,15 & 1,03 \\
\hline Lu & 0,01 & 0,01 & 0,09 & 0,14 & 0,23 & 0,21 & 0,3 & 1,76 & 0,15 \\
\hline $\mathrm{Eu} / \mathrm{Eu}^{*}$ & 1,47 & 0,36 & 0,73 & 0,39 & 0,63 & 0,88 & 0,55 & 0,52 & 0,79 \\
\hline$(\mathrm{La} / \mathrm{Yb})_{\mathrm{N}}$ & 49,81 & 8,88 & 25,92 & 8,57 & 2,11 & 2,40 & 2,71 & 1,52 & 2,70 \\
\hline
\end{tabular}

PF: perda ao fogo; $\mathrm{Mg} \#: \mathrm{MgO} /\left(\mathrm{MgO}+\mathrm{FeO}_{\mathrm{t}}\right) \mathrm{mol} ; \mathrm{Eu}^{\mathrm{E}} \mathrm{Eu}^{*}: \mathrm{Eu}_{\mathrm{N}} /\left(\left(\mathrm{Sm}_{\mathrm{N}}+\mathrm{Gd}_{\mathrm{N}}\right) / 2\right]$. 

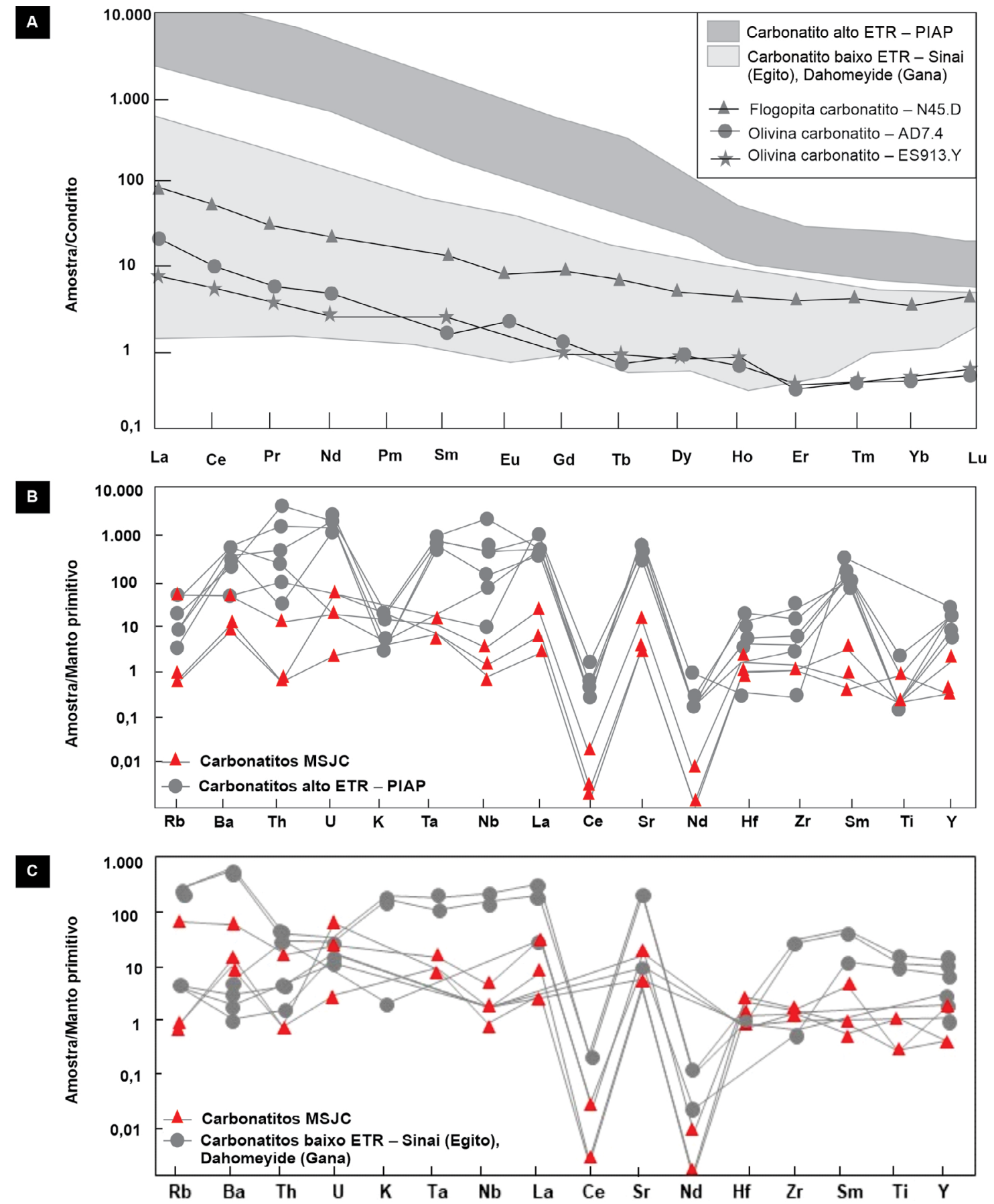

ETR: elementos terras raras; PIAP: Província Ígnea do Alto Paranaíba; MSJC: Maciço São José do Campestre.

Figura 10. Características litogeoquímicas de carbonatito. (A) Espectros das amostras N45D, AD7.4 e ES913Y dos carbonatitos do Maciço São José do Campestre e campos de carbonatito de alto elementos terras raras da Província Ígnea do Alto Paranaíba, de Grasso (2010), Gomide (2015) e Barbosa (2009), e carbonatitos de baixo elementos terras raras, de Azer et al. (2010), Boskabadi et al. (2013) e Attoh e Nude (2008), normalizados ao condrito (Sun e McDonough, 1989); (B) diagrama multielementos dos carbonatitos do Maciço São José do Campestre e dos carbonatitos de alto elementos terras raras da Província Ígnea do Alto Paranaíba, normalizados ao manto primitivo de Sun e McDonough (1989); (C) diagrama multielementos dos carbonatitos do Maciço São José do Campestre e dos carbonatitos de baixo elementos terras raras de Sinai e de Gana, normalizados ao manto primitivo de Sun e McDonough (1989). 


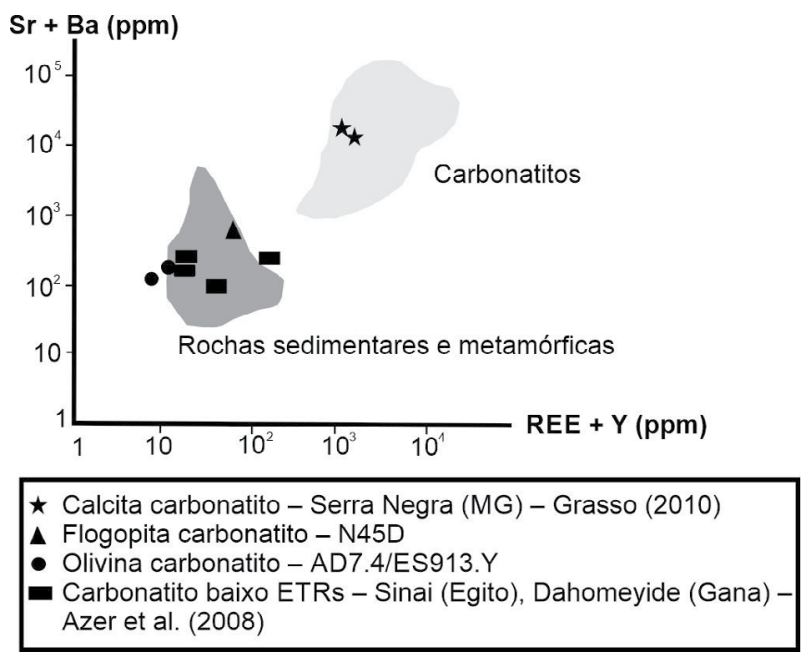

ETR: elementos terras raras.

Figura 11. Diagrama $\mathrm{Sr}+\mathrm{Ba}$ versus $\Sigma \mathrm{REE}+\mathrm{Y}$ de Samoilov (1991) mostrando os campos de rochas carbonáticas ígneas (carbonatitos) e sedimentares e metamórficas, comparação com amostras estudadas e exemplos do Egito e de Gana. compatíveis (Sr-Y), com anomalia negativa de $\mathrm{K}$, Sr e Ti (Figura 13B).

\section{GRAVIMETRIA}

Na modelagem 2D da Figura 14, o perfil A-B foi realizado perpendicular à direção de maior alongamento do corpo ultramáfico, visando melhor compreender sua geometria e relações de contato com os carbonatitos e gnaisses encaixantes. $\mathrm{O}$ contraste de densidade utiliza o método de Arquimedes (Tabela 8). O valor médio para o contraste de densidade entre o clinopiroxenito e o embasamento é de $0,472 \mathrm{~g} / \mathrm{cm}^{3}$, e entre carbonatito e clinopiroxenito, $-0,469 \mathrm{~g} /$ $\mathrm{cm}^{3}$. Esses valores foram utilizados para modelar o perfil da Figura 14.

Informações geológicas de mapeamento e sensoriamento remoto permitiram reduzir as possibilidades de interpretação, uma vez que o corpo ultramáfico, apesar de não aflorante, é delimitado por um solo de coloração escura que contrasta com o solo proveniente das rochas encaixantes. Brechas magmáticas com fragmentos de piroxenito
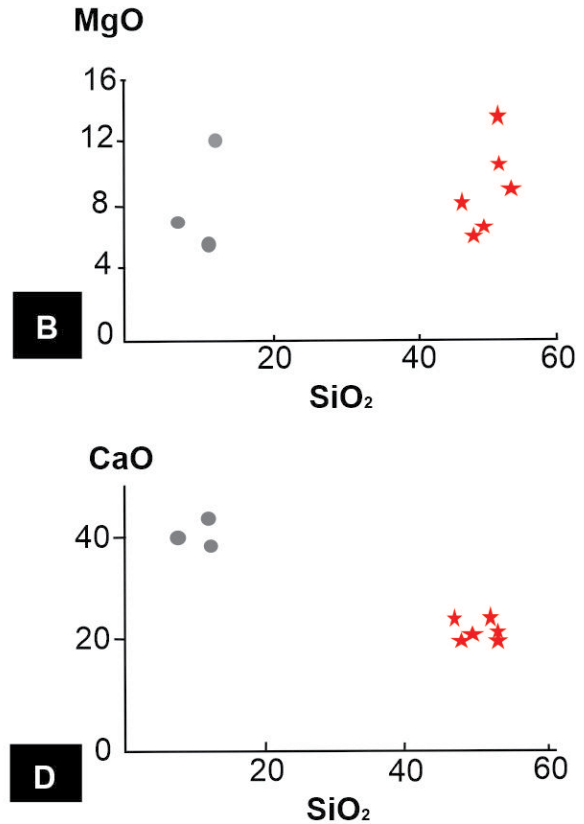

- Carbonatitos MSJC

$\star$ Clinopiroxenitos MSJC

MSJC: Maciço São José do Campestre.

Figura 12. (A) Diagrama $A F M\left(A=\mathrm{Na}_{2} \mathrm{O}+\mathrm{K}_{2} \mathrm{O}, \mathrm{F}=\mathrm{FeO}_{\mathrm{t}}, \mathrm{M}=\mathrm{MgO}\right)$ de Irvine e Baragar (1971), mostrando a afinidade toleítica dos piroxenitos; (B, C e D) diagramas de variação de Harker de elementos maiores para amostras de carbonatito e clinopiroxenito do Maciço São José do Campestre com eixos compostos de $\mathrm{MgO}, \mathrm{Al}_{2} \mathrm{O}_{3}$ e $\mathrm{CaO}$. 

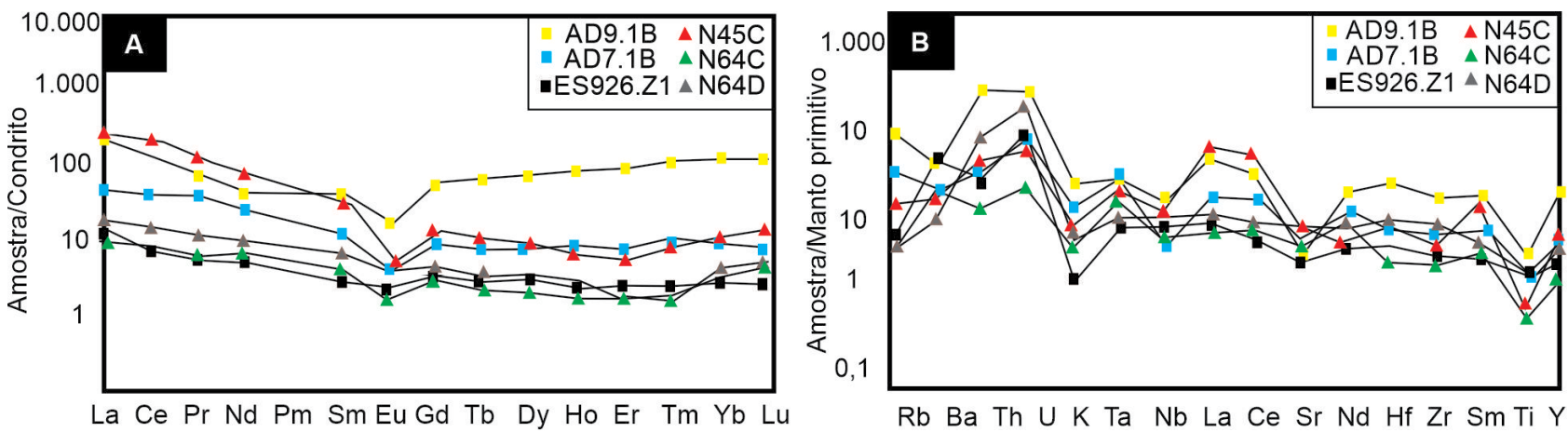

Figura 13. Características litogeoquímicas de clinopiroxenito. (A) Espectro de elementos terras raras normalizados ao condrito de Sun e McDonough (1989); (B) diagramas multielementares normalizados ao manto primitivo de Sun e McDonough (1989) indicando anomalia negativa de K, Sr e Ti.

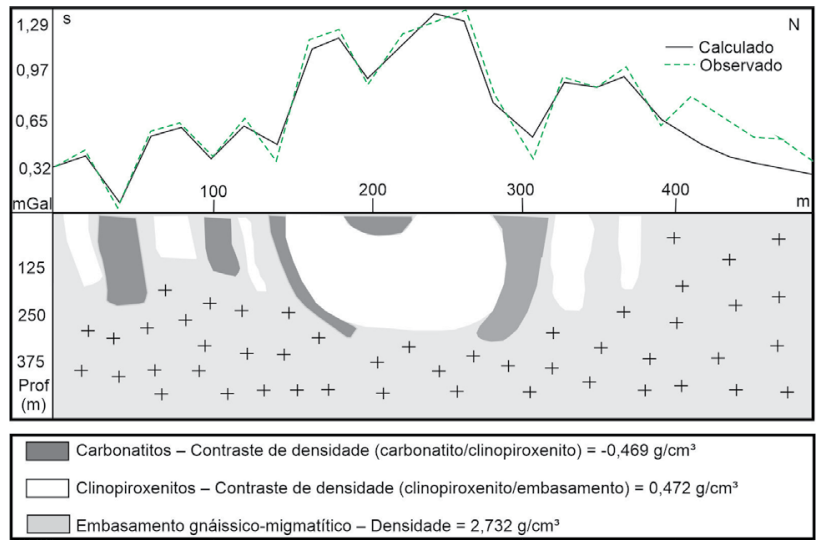

Figura 14. Modelagem gravimétrica 2D de um perfil $\mathrm{N}-\mathrm{S}$ que corta o corpo ultramáfico perpendicularmente (Figura 2). Nesse modelo, o corpo principal está em contato direto com carbonatitos, enquanto as extremidades são marcadas por corpos de menor expressividade.

englobados por carbonatito (Figura 3 ) evidenciam a relação direta entre esses dois tipos litológicos, atestando a proximidade espacial entre elas, característica refletida em picos de anomalia Bouguer observados ao longo do perfil gravimétrico.

$\mathrm{Na}$ interpretação geológica do resultado da modelagem 2D da Figura 14, o corpo ultramáfico localizado na porção central possui forma elíptica, com extremidades e centro compostos de pequenos corpos carbonatíticos, inferidos a partir do contraste de densidade. Apesar de não expressar altos valores de densidade no perfil, uma vez que possuem menor volume, corpos piroxeníticos foram admitidos nas regiões periféricas tendo como base a ocorrência de outros corpos ultramáficos nas proximidades. Trabalhos de Andersson e Malehmir (2017) foram utilizados para corroborar essa hipótese, uma vez que a partir de dados gravimétricos e aeromagnéticos, os referidos autores demonstram uma geometria para complexos carbonatíticos com um corpo de maior expressividade e outros subordinados na forma de ramificações menos expressivas em superfície. De modo semelhante, percebe-se que o clinopiroxenito possui maior volume para essa região, atestado pela resposta gravimétrica e por dados geológicos, além de possuir possíveis ramificações que não estão, necessariamente, ligadas ao corpo principal.

$\mathrm{O}$ resultado da modelagem sugere duas diferentes relações de contato entre o clinopiroxenito e o carbonatito. A primeira, localizada no centro do perfil, apresenta lentes de carbonatito nas extremidades e no centro. Na segunda, localizada nas extremidades, os corpos possuem menores espaçamentos entre si. Entretanto, ressalta-se que esse comportamento não é visualizado em campo, uma vez que as extremidades do perfil são compostas de um solo claro típico do intemperismo de rocha gnáissica félsica do embasamento. Como resultado da modelagem, pode-se observar que os carbonatitos posicionados nas bordas do corpo principal de clinopiroxenito (centro do perfil) e o próprio clinopiroxenito possuem cerca de $250 \mathrm{~m}$ de profundidade, enquanto a lente central de carbonatito tem profundidade de $50 \mathrm{~m}$. Por outro lado, os corpos localizados nas extremidades do perfil foram modelados com profundidade de cerca de $150 \mathrm{~m}$.

\section{DISCUSSÃO}

Rochas carbonáticas e ultramáficas de idade arqueana ocorrem no MSJC na forma de mármores calcíticos a dolomíticos, metanfibolitos, metagabros e piroxenitos ricos em ferro (Jesus, 2011; Figueiredo, 2012; Ferreira, 2015; Abrahão Filho, 2016). Entretanto, carbonatitos do CSES datados em $600 \pm$ $3 \mathrm{Ma}$ (Souza et al., 2018), associados com clinopiroxenitos 
Tabela 8. Média de densidades das amostras coletadas no corpo estudado.

\begin{tabular}{|c|c|c|c|c|c|c|c|}
\hline Amostra & Litologia & $\begin{array}{l}\text { Bloco } 1 \\
\left(\mathrm{~g} / \mathrm{cm}^{3}\right)\end{array}$ & $\begin{array}{l}\text { Bloco } 2 \\
\left(\mathrm{~g} / \mathrm{cm}^{3}\right)\end{array}$ & $\begin{array}{l}\text { Bloco } 3 \\
\left(\mathrm{~g} / \mathrm{cm}^{3}\right)\end{array}$ & $\begin{array}{c}\text { Número de } \\
\text { medição/bloco }\end{array}$ & $\begin{array}{c}\text { Média das } \\
\text { densidades }\left(\mathrm{g} / \mathrm{cm}^{3}\right)\end{array}$ & $\sigma$ \\
\hline N64K & Carbonatito & 2,730 & 2,740 & - & 3 & 2,735 & 0,005 \\
\hline N64J & Clinopiroxenito & 3,204 & 3,148 & 3,213 & 3 & 3,204 & 0,029 \\
\hline N65W & $\begin{array}{c}\text { Clinopiroxênio- granada- } \\
\text { ortognaisse }\end{array}$ & 2,707 & 2,732 & 2,733 & 3 & 2,732 & 0,012 \\
\hline
\end{tabular}

de textura compacta com pouca ou nenhuma deformação, apresentam diferenças composicionais, texturais e geocronológicas, sugerindo a ocorrência de um evento magmático carbonático-ultramáfico ediacarano no MSJC.

Os clinopiroxenitos são marcados por eventos metamórficos indicados pela ocorrência de simplectitos de clinopiroxênio e plagioclásio gerados a partir de reações retrógradas na paragênese inicial dessas rochas, além de cristais de clinopiroxênio sofrendo processos de substituição mineral para anfibólio em processos pontuais de uralitização. Granada parcialmente consumida formando escapolita também é configurada como uma textura retrogressiva. Nos carbonatitos, a recristalização de calcita, a deformação de flogopita e a serpentinização de olivina atestam a atuação de metamorfismo e metassomatismo. Dessa forma, interpreta-se que essas rochas, após intrusão, sofreram resfriamento em altas temperaturas, seguido pela atuação de processos metassomáticos e retrogressão com influência de fluidos ricos em $\mathrm{CO}_{2}$ e $\mathrm{H}_{2} \mathrm{O}$.

Diagramas tipo Harker e AFM indicam magma toleítico, com forte enriquecimento em ferro para os clinopiroxenitos, além de empobrecimento de $\mathrm{MgO}$ no líquido magmático. Os carbonatitos, por sua vez, possuem comportamento geoquímico e composicional distinto, configurando um grupo diferente nesse diagrama, sugerindo uma evolução a partir de dois líquidos, um carbonatítico e outro silicático.

Apesar de os estudos geoquímicos atestarem o forte enriquecimento de ETR em rochas carbonatíticas como característica distintiva, carbonatitos com baixas concentrações de ETR são descritos no mundo (e.g., Attoh e Nude, 2008; Azer et al., 2010; Boskabadi et al., 2013), uma vez que não representam as fases mais evoluídas desse magmatismo e, assim, não possuem valores significativos desses elementos. Segundo Boskabadi et al. (2013), o baixo conteúdo de ETR em carbonatitos pode ser explicado:

- pela perda pós-magmática por recristalização de carbonato;

- como característica de fontes primárias;

- pelo reflexo da composição do manto litosférico.

Assim, o potencial de mineralização dos carbonatitos está diretamente relacionado às condições de geração dessa rocha. Contudo, carbonatitos não mineralizados são utilizados para a produção de cal e cimento, a exemplo Tororo (Uganda) e Xiluvo (Moçambique) (van Straaten, 2002).

Segundo Damasceno (2017), depósitos de Cr, Pt, Pd, $\mathrm{Ni}-\mathrm{Cu}, \mathrm{Ti}-\mathrm{Fe}$ e cromita podiformes estão associados às rochas máficas e ultramáficas. Além disso, rochas silicáticas ricas em $\mathrm{P}, \mathrm{K}, \mathrm{Ca}$ e $\mathrm{Mg}$, por meio de técnicas de rochagem, são utilizadas como modificadores de solo (rejuvenescimento e remineralização) a fim de aumentar a fertilidade do solo e o processo de produção agrícola (Theodoro et al., 2006). No MSJC, Abram et al. (2011) revelam a presença de fosfato nos clinopiroxenitos por meio de testes com molibdato de amônia, o que sugere um potencial exploratório.

O modelo bidimensional do corpo ultramáfico e das rochas carbonatíticas gerado a partir de interpretação gravimétrica é sensível às correlações observadas em campo. Nesse contexto, compreende-se que o resultado final expressa uma possibilidade no que diz respeito ao formato dos corpos e nas suas relações de contato. Contudo, a associação do modelo gravimétrico com os limites litológicos definidos em campo permite inferir um modelo carbonatítico do tipo central. Assim, justifica-se que os carbonatitos, por serem menos expressivos, ocorrem como rochas subordinadas na forma de pequenos veios anelares contornando o corpo piroxenítico. Além disso, sugere-se a ocorrência de outros corpos carbonatíticos e ultramáficos ainda não identificados em volta do corpo ultramáfico principal a partir da correlação com complexos carbonatíticos do tipo central (Figura 15A). Este, definido por Lapin e Ploshko (1988), consiste em uma distribuição anelar das rochas constituintes, em que os carbonatitos se apresentam na forma de diques, veios anelares, stocks ou plugs (Figura 15B).

A partir do modelo gravimétrico, infere-se que os carbonatitos do CSES estão distribuídos nas porções laterais e no centro do corpo piroxenítico, consistindo em aproximadamente cinco corpos subparalelos de direção E-W e com extensão inferior a $300 \mathrm{~m}$. Amostras de carbonatito encontradas nas proximidades (N45) são marcadas por xenólitos de piroxenito que possuem formas irregulares, como observado na Figura 3, atestando a relação entre essas litologias. Ocorrência de outras formas de carbonatito, como diques nas rochas encaixantes, não foi observada. 


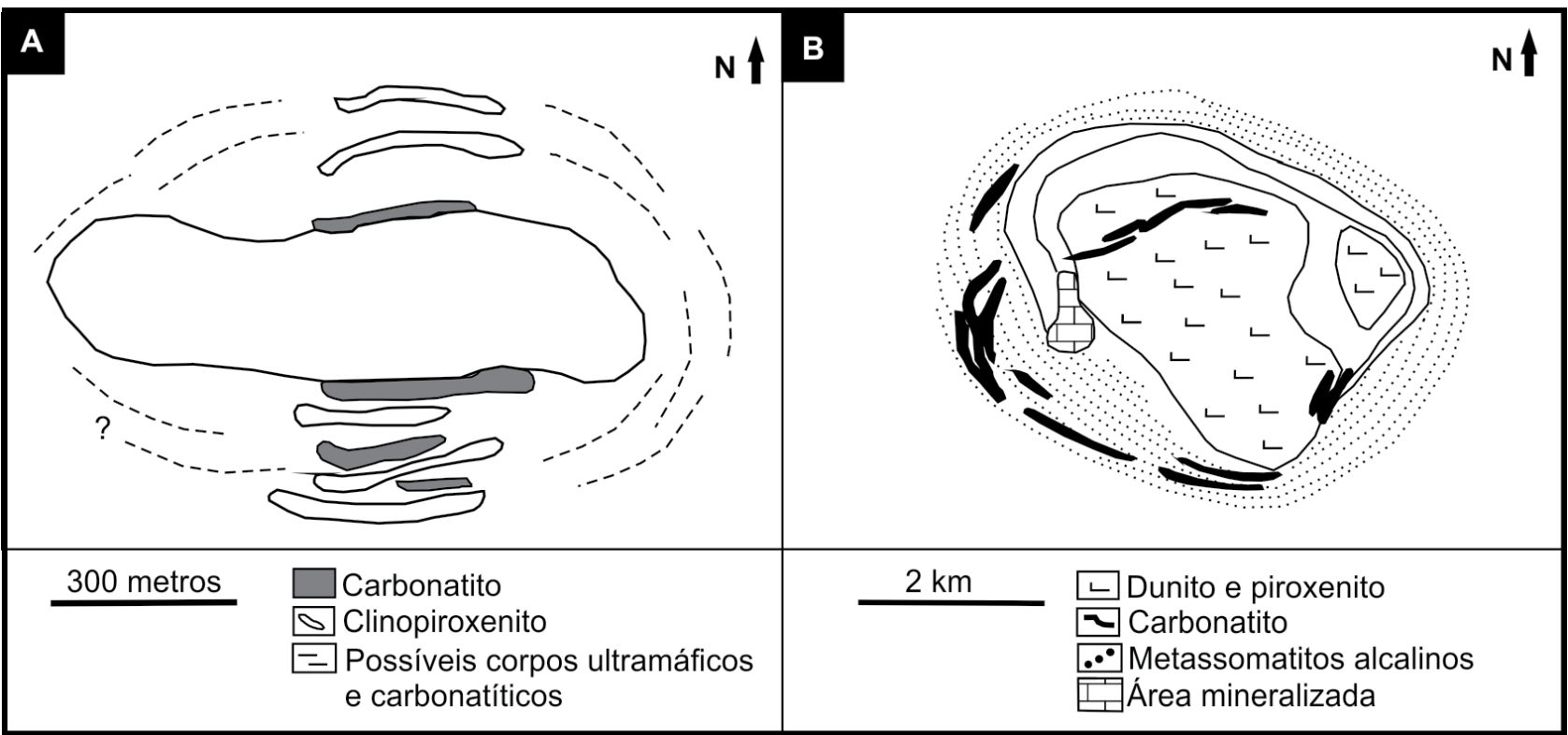

Figura 15. Geometria de carbonatitos visto em planta. (A) Modelo interpretado para a relação entre rochas ultramáficas e carbonatíticas do Complexo Senador Elói de Souza; (B) modelo do corpo carbonatítico do tipo central (Lapin e Ploshko, 1988). Nos dois exemplos, os carbonatitos bordejam a intrusão principal.

\section{CONCLUSÕES}

Com base no conjunto de informações reportadas neste trabalho, é possível listar as seguintes conclusões:

- a ocorrência de xenólitos de piroxenito em blocos de carbonatito é uma forte evidência de sua natureza ígnea, que é corroborada pela presença de textura ígnea preservada;

- os clinopiroxenitos são formados essencialmente por hedenbergita, contendo quantidades variadas de escapolita e granada e venulações de calcita;

- os carbonatitos possuem como mineral essencial a calcita, além de quantidades subordinadas de diopsídio, flogopita, olivina e traços de apatita e granada; clinopiroxenitos e carbonatitos possuem diferentes comportamentos composicionais e geoquímicos atestados por diferentes proporções de $\mathrm{Al}_{2} \mathrm{O}_{3}, \mathrm{CaO}, \mathrm{MgO}$ e $\mathrm{SiO}_{2}$. As rochas ultramáficas deste trabalho possuem afinidade toleítica, anomalias de európio e anomalias negativas de K, Sr e Ti;

- a modelagem gravimétrica permitiu inferir que o corpo estudado possui forma elipsoidal, além de estar associado com outros corpos piroxeníticos e carbonatitos de menor expressividade;

- sugerem-se estudos mais aprofundados para o melhor conhecimento da relação de contato entre essas litologias e para compreender a história geológica que envolve esse corpo ultramáfico e a eventual possibilidade de existência de depósitos minerais de valor econômico.

\section{AGRADECIMENTOS}

Os autores agradecem ao Programa de Pós-Graduação em Geodinâmica e Geofísica e ao Departamento de Geologia da Universidade Federal do Rio Grande do Norte (UFRN) a infraestrutura disponibilizada; ao Prof. Dr. Nilson Botelho a aquisição de dados de microssonda eletrônica no Instituto de Geociências da Universidade de Brasília; ao Prof. Dr. Walter Eugênio Medeiros (DGef/UFRN) a colaboração na aquisição e na interpretação geofísica; e ao Conselho Nacional de Desenvolvimento Científico e Tecnológico (CNPq), por meio do projeto 408607/2018-1 (coordenado por ZSS).

\section{REFERÊNCIAS}

Abrahão Filho, E. A. (2016). Rochas piroxeniticas ricas em ferro do maciço São José do Campestre, Rio Grande do Norte, Brasil. Dissertação (Mestrado). Brasília: Instituto de Geociências - UnB. Disponível em: https://repositorio.unb. br/handle/10482/22068. Acesso em: 24 set 2021. 
Abram, M. B., Bahiense, I. C., Porto, C. G., Brito, R. S. C. (2011). Projeto Fosfato Brasil Parte 1. Salvador: CPRM.

Almeida, F. F. M., Hasui, Y., Brito Neves, B. B., Fuck, R. A. (1981). Brazilian structural provinces: an introduction. Earth Science Reviews, 17(1-2), 1-29. https://doi. org/10.1016/0012-8252(81)90003-9

Andersson, M., Malehmir, A. (2017). Unravelling the internal architecture of the Alnö alkaline and carbonatite complex (central Sweden) using 3D models of gravity and magnetic data. Solid Earth Discuss. https://doi.org/10.5194/ se-2017-3

Araújo, I. L., Moraes, R. A. V., Dantas, E. L., Vidotti, R. M., Fuck, R. A. (2014). Tectonic framework of the São José of Campestre Massif, Borborema Province, based on new aeromagnetic data. Revista Brasileira de Geofisica, 32(3), 445-463. https://doi.org/10.22564/rbgf.v32i3.502

Attoh, K., Nude, P. M. (2008). Tectonic significance of carbonatite and ultrahigh-pressure rocks in the Pan-African Dahomeyide suture zone, southeastern Ghana. Geological Society, 297, 217-231. https://doi.org/10.1144/SP297.10

Azer, M. K., Stern, R. J., Kimura, J. (2010). Origin of a late Neoproterozoic $(605+/-13 \mathrm{Ma})$ intrusive carbonatealbite complex in Southern Sinai, Egypt. Journal of Earth Science, 99, 245-267. https://doi.org/10.1007/ s00531-008-0385-1

Barbosa, E. S. R. (2009). Mineralogia e petrologia do complexo carbonatítico-foscoritico de Salite, $M G$. Tese (Doutorado). Brasília: Instituto de Geociências - UnB. Disponível em: https://repositorio.unb.br/handle/10482/10379. Acesso em: 24 set. 2021.

Barker, D. S. (1989). Field relations of carbonatites. In: K. Bell (ed.). Carbonatites: genesis and evolution. London: Unwin Hyman.

Boskabadi, A., Pitcairn, I. K., Stern, R. J., Azer, M. K., Broman, C., Mohamed, F. H., Majka, J. (2013). Carbonatite crystallization and alteration in the Tarr carbonatitealbitite complex, Sinai Peninsula, Egypt. Precambrian Research, 239, 24-41. https://doi.org/10.1016/j. precamres.2013.09.001

Brito Neves, B. B., Santos, E. J., Van-Schmus, W. R. (2000). Tectonic history of the Borborema Province, Northeastern Brazil. In: U. Cordani, E. J. Milani, A. Thomaz Filho, D. A. Campos (Eds.). Tectonic evolution of South America. Rio de Janeiro: 31 st International Geological Congress.
Caby, R. (1989). Precambrian terranes of Benin-Nigeria and Northeast Brazil and the late Proterozoic south Atlantic fit. In: R. D. Dallmeyer (Ed.), Terranes in the circumAtlantic Paleozoic orogens, v. 230, p. 145-158. Geological Society of America Special Papers. https://doi.org/10.1130/ SPE230-p145

Caby, R., Sial, A. N., Arthaud, M., Vauchez, A. (1991). Crustal evolution and the Brasiliano Orogeny in Northeast Brazil. In: R. D. Dallmeyer, J. P. Lécorché (Eds.), The West African Orogens and Circum-Atlantic Correlatives, p. 373-397. Berlin: Springer-Verlag. https://doi. org/10.1007/978-3-642-84153-8_16

Cooper, G. R. J. (2003). GRAV2dc para Microsoft Windows (versão 2.06). Johannesburg: Departamento de Geofísica, Universidade de Witwatersrand. Disponível em: https://grav2d.software.informer.com/2.1/. Acesso em: 20 out. 2010.

Cunha, J. A. P. (2015). Caracterização geológica e petrográfica de sovitos de uma área a $N W$ de São José do Campestre, $R N$. Monografia (Graduação). Natal: Departamento de Geologia - UFRN.

Damasceno, G. C. (2017). Geologia, mineração e meio ambiente. Cruz das Almas: UFRB, 64 p. Disponível em: https://www2.ufrb.edu.br/ead/images/imagensACESSE/ Geologia_Minera\%C3\%A7\%C3\%A3o_e_Meio_Ambiente. pdf. Acesso em: 9 set. 2021.

Dantas, E. L., Souza, Z. S., Wernick, E., Hackspacher, P. C., Martin, H., Xiaodong, D., Li, J. (2013). Crustal growth in the 3.4-2,7 Ga São José do Campestre Massif, Borborema Province, NE do Brazil. Precambrian Research, 227, 120 156. https://doi.org/10.1016/j.precamres.2012.08.006

Dantas, E. L., Van Schmus, W. R., Hackspacher, P. C., Fetter, A. H., Brito Neves, B. B., Cordani, U. G., Nutman, A. P., Willyams, I. S. (2004). The 3.4-3.5 Ga São José do Campestre massif, NE Brazil: remnants of the oldest crust in South America. Precambrian Research, 130(1-4), 113137. https://doi.org/10.1016/j.precamres.2003.11.002

Deer, W. A., Howie, R. A., Zussman, J. (2013). An introduction to rock-forming minerals. Essex: Longman.

Ferreira, A. C. D. (2015). Intrusões máficas-ultramáficas do dominio Rio Grande do Norte, província Borborema: ambiente tectônico e potencial para depósitos magmáticos. Dissertação (Mestrado). Brasília: Instituto de Geociências - UnB. Disponível em: https://repositorio.unb.br/handle/10482/19805. Acesso em: 24 set. 2021. 
Figueiredo, B. S. (2012). Geoquímica e gênese das formações ferriferas e metacarbonatos da porção sul do Maciço São José do Campestre, Província Borborema. Dissertação (Mestrado). Brasília: Instituto de Geociências - UnB. Disponível em: https://repositorio.unb.br/handle/10482/12332. Acesso em: 24 set. 2021.

Gill, R. (2014). Rochas e processos igneos: um guia prático. Chichester: Bookman.

Gomide, C. S. (2015). Geoquímica e química mineral de carbonatitos e isótopos estáveis em carbonatítos da provincial ignea do Alto Paranaiba. Tese (Doutorado). Brasília: Instituto de Geociências - UnB. Disponível em: https://repositorio. unb.br/handle/10482/20104. Acesso em: 24 set. 2021.

Grasso, C. B. (2010). Petrologia do complexo alcalinocarbonatítico de Serra Negra, MG. Tese (Doutorado). Brasília: Instituto de Geociências - UnB. Disponível em: https://repositorio.unb.br/handle/10482/8446. Acesso em: 24 set. 2021.

Irvine, T. N., Baragar, W. R. A. (1971). A guide to the chemical classification of the common volcanic rocks. Canadian Journal Earth Sciences, 8(5), 523-548. https:// doi.org/10.1139/e71-055

Jesus, B.A. (2011). Rochas Máficas e Ultramáficas do Complexo Riacho Da Telha, Maciço São José Do Campestre, Província Borborema, NE Do Brasil. Dissertação (Mestrado). Brasília: Instituto de Geociências - UnB. Disponível em: https:// repositorio.unb.br/handle/10482/9364. Acesso em: 24 set. 2021.

Lapin, A. V., Ploshko, V. V. (1988). Rock-association and morphological types of carbonatite and their geotectonic environments. International Geology Review, 30(4), 390396, https://doi.org/10.1080/00206818809466019

Le Bas, M. J. (1981). Carbonatite magmas. Mineralogical Magazine, 44(334), 133-140. https://doi.org/10.1180/ minmag.1981.044.334.02

Le Maitre, R. W. (2002). Igneous rocks: a classification and glossary of terms recommendations of the internetion union of Geological Sciences, Subcommission on the Systematics of Igneous Rocks. Cambridge: Cambridge University Press. https://doi.org/10.1017/CBO9780511535581

Le Maitre, R. W., Bateman, P., Dudek, A., Keller, J., Lameyre, J., Le Bas, M. J., Sabine, P. A., Schmid, R., Sorensen, H., Streckeisen, A., Wooley, A. R., Zanettin, B. (1989). A classification of igneos rocks and glossary of terms. Reino Unido: Blackwell Scientific, IUGS.
Moazzen, M., Oberhansli, R., Hajialioghli, R. M., Bousquet, R., Droop, G., Jahangiri, A. (2009). Peak and post-peak PT conditions and fluid composition for scapolite-clinopyroxenegarnet calc-silicate rocks from the Takab area, NW Iran. European Journal of Mineralogy, 21(1), 149-162. https:// doi.org/10.1127/0935-1221/2009/0021-1919

Morimoto, N., Fabries, J. A., Ferguson, A. K., Ginzburg, I. V., Ross, M., Seifert, F. A., Zussman, J., Aoki, K., Gottardi, G. (1988). Nomenclature of pyroxenes. Mineralogical Magazine, 52(367), 535-550. https://doi.org/10.1180/ minmag.1988.052.367.15

Samoilov, V. S. (1991). The main geochemical features of carbonatites. Journal of Geochemical Exploration, 40(1-3), 251-262. https://doi.org/10.1016/0375-6742(91)90041-R

Silva, M. S. M. (2017). Mapeamento geológico da área de Tangará a Sítio Novo (RN) com ênfase na porção $S W$ do Núcleo Arqueano São José do Campestre, NE do Brasil. Monografia (Graduação). Natal: Departamento de Geologia - UFRN.

Souza, A. L. O. (2018). Caracterização geológica de rochas carbonáticas no núcleo arqueano, São José do Campestre (RN), NE do Brasil. Monografia (Graduação). Natal: Departamento de Geologia - UFRN.

Souza, Z. S., Kalsbeek, F., Deng, X, Frei, R., Kokfelt, T. F., Dantas, E. L., Li, J., Pimentel, M. M., Galindo, A. C. (2016). Generation of continental crust in the northern part of the Borborema Province, northeastern Brazil, from Archaean to Neoproterozoic. Journal of South American Earth Sciences, 68, 68-96. https://doi.org/10.1016/j. jsames.2015.10.006

Souza, Z. S., Oliveira, E. P., Vilalva, F. C. J. (2018). Idades $\mathrm{U}-\mathrm{Pb}$ ediacaranas de carbonatitos do Núcleo Arqueano São José do Campestre/RN, NE do Brasil; implicações geodinâmicas. XLIX Congresso Brasileiro de Geologia. Rio de Janeiro: SBG.

Speer, J. A. (1984). Micas in igneous rocks. In: S. W. Bailey (Ed.). Reviews in Mineralogy, v. 13, p. 299-356. Blacksburg: Mineralogical Society of America.

Sun, S. S., McDonough, W. F. (1989). Chemical and isotope systematics of oceanic basalts: implications for mantle composition and processes. In: A. D. Saunders, M. J. Norry (Eds.). Magmatism in the ocean basins, 42(1), 313-345. Special Publication. Londres: Geological Society of London. https://doi.org/10.1144/ GSL.SP.1989.042.01.19 
Talwani, M., Worzel, J. M., Landisman, M. (1959). Rapid gravity computations for two-dimensional bodies with application to the Mendocino Submarine Fracture Zone. Journal of Geophysical Research, 64(1), 49-59. https://doi. org/10.1029/JZ064i001p00049

Teertstra, D. K., Schindler, M., Sherriff, B. L., Hawthorne, F. C. (1999). Silvialite, a new sulfate-dominant member of the scapolite group with an Al-Si composition near the I4/mP42/n phase transition. Mineralogical Magazine, 63(3), 321329. https://doi.org/10.1180/002646199548547

Teixeira, F. B. (2012). Geologia e petrografia de complexos carbonatíticos intrusivos no Maciço São José do Campestre, Nordeste do Brasil. Monografia (Graduação). Natal: Departamento de Geologia - UFRN.

Theodoro, S. M. C. H., Leonardos, O. H., Rocha, E. L., Rego, K. G. (2006). Experiências de uso de rochas silicáticas como fonte de nutrientes. Espaço \& Geografia, 9(2), 263-292.
Disponível em: https://repositorio.unb.br/handle/10482/20882. Acesso em: $1^{\circ}$ nov. 2020.

van Straaten, P. (2002). Rocks for Crops: Agrominerals of sub-Saharan Africa. Nairóbi: ICRAF. Disponível em: http:// apps.worldagroforestry.org/Units/Library/Books/PDFs/11 Rocks_for_crops.pdf. Acesso em: $1^{\circ}$ nov. 2020.

Viegas, M. C. (2007). Síntese geológica do leste do Rio Grande do Norte na escala 1:250.000. Monografia (Graduação). Natal: Departamento de Geologia - UFRN.

Woolley, A. R., Kempe, D. R. C. (1989). Carbonatites: nomenclature, average chemical composition, and elemete distribution. In: K. Bell (Ed.). Carbonatites: genesis and evolution, p. 1-14. Londres: Unwin Hyman.

Woolley,A. R., Kjarsgaard, B.A. (2009). Carbonatite occurrences of the world: Map and Database. Journal of Petrology, 50(1), 195-196. https://doi.org/10.1093/petrology/egn080 